\title{
TU/e emonownen

\section{Convex modeling and sizing of electrically supercharged internal combustion engine powertrain}

\section{Citation for published version (APA):}

Marinkov, S., Murgovski, N., \& de Jager, B. (2016). Convex modeling and sizing of electrically supercharged internal combustion engine powertrain. IEEE Transactions on Vehicular Technology, 65(6), 4523-4534. https://doi.org/10.1109/TVT.2015.2510510

DOI:

10.1109/TVT.2015.2510510

Document status and date:

Published: 16/06/2016

\section{Document Version:}

Accepted manuscript including changes made at the peer-review stage

\section{Please check the document version of this publication:}

- A submitted manuscript is the version of the article upon submission and before peer-review. There can be important differences between the submitted version and the official published version of record. People interested in the research are advised to contact the author for the final version of the publication, or visit the $\mathrm{DOI}$ to the publisher's website.

- The final author version and the galley proof are versions of the publication after peer review.

- The final published version features the final layout of the paper including the volume, issue and page numbers.

Link to publication

\section{General rights}

Copyright and moral rights for the publications made accessible in the public portal are retained by the authors and/or other copyright owners and it is a condition of accessing publications that users recognise and abide by the legal requirements associated with these rights.

- Users may download and print one copy of any publication from the public portal for the purpose of private study or research.

- You may not further distribute the material or use it for any profit-making activity or commercial gain

- You may freely distribute the URL identifying the publication in the public portal.

If the publication is distributed under the terms of Article 25fa of the Dutch Copyright Act, indicated by the "Taverne" license above, please follow below link for the End User Agreement:

www.tue.nl/taverne

Take down policy

If you believe that this document breaches copyright please contact us at:

openaccess@tue.nl

providing details and we will investigate your claim. 


\title{
Convex modeling and sizing of electrically supercharged internal combustion engine powertrain
}

\author{
Sava Marinkov, Nikolce Murgovski and Bram de Jager
}

\begin{abstract}
This paper investigates a concept of an electrically supercharged internal combustion engine powertrain. A supercharger consists of an electric motor and a compressor. It draws its power from an electric energy buffer (e.g., a battery) and helps the engine during short-duration high-power demands. Both the engine and the buffer are sized to reduce the sum of the vehicle operational (fuel) and component (engine and buffer) costs. For this purpose, a convex, driving cycle-based vehicle model is derived, enabling the formulation of an underlying optimization problem as a second order cone program. Such a program can be efficiently solved using dedicated numerical tools (for a given gear selection strategy), which provides not only the optimal engine/buffer sizes but also the optimal vehicle control and state trajectories (e.g., compressor power and buffer energy). Finally, the results obtained from a representative, numerical case study are discussed in detail.
\end{abstract}

\section{NOMENCLATURE}

$\begin{array}{ll}\text { BL } & \text { Baseline. } \\ \text { DS } & \text { Downsized. } \\ \text { NA } & \text { Naturally-aspirated. } \\ \text { SC } & \text { Supercharged. } \\ A & \text { Area. } \\ C & \text { Capacitance. } \\ E & \text { Energy. } \\ H & \text { Heating value. } \\ J & \text { Cost function. } \\ L & \text { Gear ratio set. } \\ P & \text { Power. } \\ Q & \text { Charge. } \\ R & \text { Electrical resistance. } \\ T & \text { Temperature. } \\ V & \text { Volume. } \\ a & \text { Linear acceleration. } \\ c & \text { Constant coefficient. } \\ m & \text { Mass. } \\ \dot{m} & \text { Mass flow. } \\ p & \text { Pressure. } \\ r & \text { Radius. } \\ s & \text { Scaling variable. } \\ s o c & \text { State-of-charge. } \\ t & \text { Time. } \\ u & \text { Voltage. } \\ v & \text { Linear velocity. } \\ & \end{array}$

Copyright (c) 2015 IEEE. Personal use of this material is permitted. However, permission to use this material for any other purposes must be obtained from the IEEE by sending a request to pubs-permissions@ieee.org.

Sava Marinkov and Bram de Jager are with the Department of Mechanical Engineering, Eindhoven University of Technology, Eindhoven, The Netherlands (e-mail: s.marinkov@tue.nl; a.g.de.jager@tue.nl.).

Nikolce Murgovski is with the Department of Signals and Systems, Chalmers University of Technology, Gothenburg, Sweden (e-mail: nikolce.murgovski@chalmers.se).

\begin{tabular}{|c|c|}
\hline$w$ & Weighting coefficient. \\
\hline$\gamma$ & Varying coefficient. \\
\hline$\eta$ & Efficiency. \\
\hline$\lambda$ & Ratio. \\
\hline$\mu$ & Price. \\
\hline$\omega$ & Rotational velocity. \\
\hline$\rho$ & Density. \\
\hline$\tau$ & Torque. \\
\hline$(\hat{\cdot})$ & Approximate. \\
\hline$(\cdot)$ & Baseline/mean effective. \\
\hline$(\cdot)^{c}$ & Chemical. \\
\hline$(\cdot)^{e}$ & Electrical. \\
\hline$(\cdot)^{m}$ & Mechanical. \\
\hline$(\cdot)_{\mathrm{A}}$ & Alternator. \\
\hline$(\cdot)_{\mathrm{AM}}$ & Ambient (air). \\
\hline$(\cdot)_{\mathrm{AU}}$ & Auxiliary. \\
\hline$(\cdot)_{\mathrm{B}}$ & Electric energy buffer. \\
\hline$(\cdot)_{\mathrm{BR}}$ & Brake. \\
\hline$(\cdot)_{\mathrm{C}}$ & Compressor. \\
\hline$(\cdot)_{\mathrm{E}}$ & Engine. \\
\hline$(\cdot)_{\mathrm{EM}}$ & Exhaust manifold. \\
\hline$(\cdot)_{\mathrm{G}}$ & Gearbox. \\
\hline$(\cdot)_{\mathrm{IM}}$ & Intake manifold. \\
\hline$(\cdot)_{\mathrm{M}}$ & Motor. \\
\hline$(\cdot)_{\mathrm{ML}}$ & Mechanical link. \\
\hline$(\cdot)_{\mathrm{V}}$ & Vehicle. \\
\hline$(\cdot)_{\mathrm{W}}$ & Wheel. \\
\hline$(\cdot)$ end & End. \\
\hline$(\cdot)_{\text {life }}$ & Life-cycle. \\
\hline$(\cdot)_{\text {surge }}$ & Compressor surge. \\
\hline$(\cdot)_{\mathrm{vol}}$ & Volumetric. \\
\hline$(\cdot)_{\text {year }}$ & Year. \\
\hline$(\cdot)_{R}$ & Specific gas constant of air. \\
\hline$(\cdot)_{c}$ & Cell (electric). \\
\hline$(\cdot)_{d}$ & Drag. \\
\hline$(\cdot)_{e c}$ & Compression ratio. \\
\hline$(\cdot)_{f}$ & Frontal. \\
\hline$(\cdot)_{g}$ & Gravity. \\
\hline$(\cdot)_{l}$ & Lower. \\
\hline$(\cdot)_{\min }$ & Minimum. \\
\hline$(\cdot)_{\max }$ & Maximum. \\
\hline$(\cdot)_{p}$ & Specific heat constant of air (at const. pressure). \\
\hline$(\cdot)_{r}^{r}$ & Rolling resistance. \\
\hline$(\cdot)_{\alpha}$ & Air. \\
\hline$(\cdot)_{\kappa}$ & Specific heat ratio of air. \\
\hline$(\cdot)_{\phi}$ & Fuel. \\
\hline$(\cdot)_{\Pi}$ & Pressure ratio. \\
\hline
\end{tabular}




\section{INTRODUCTION}

Recent years have shown high interest in the reduction of energy consumption and pollutant emissions of ground transportation. With the goal of improving energy efficiency and employing renewable energy sources, vehicle manufacturers are currently introducing several types of electrified vehicles. Nevertheless, internal combustion engines (ICE) are expected to remain the dominant force in the automotive market for the next decade [1].

To meet the ever-tightening expectations on the vehicle fuel economy, the automotive industry has pursued the path of engine downsizing [2]. The engine downsizing has been typically followed by the ICE overpowering, e.g., by means of torque boosting [3], [4], to improve the vehicle drivability. In general, the application of the ICE downsizing and overpowering results in lower carbon emissions and a better fuel economy, w.r.t. the original, large engine situation - due to the reductions in the engine weight, friction and pumping losses [5]. The ICE overpowering can be also achieved using intake air boosting, with the help of a turbocharger (driven by hot exhaust gases) or a supercharger (driven mechanically by a crankshaft via a chain or a belt). In both cases, a compressor is utilized to increase (boost) the pressure/density of air supplied to the engine and thus provide it with more oxygen. This allows more fuel to be injected and burned, thereby rising the ICE maximum torque and power limits.

However, the turbocharged ICEs exhibit a relatively poor torque capability at low engine speeds, which compromises the vehicle drivability and acceleration performance [6]. Namely, at low speed, the downsized ICEs suffer from insufficient exhaust gas-flow to adequately propel the turbocharger from the moment the gas pedal is pressed, resulting in a wellknown turbo-lag [2]. The belt-driven supercharger, on the other hand, does not experience this phenomenon but is less fuel economic, as it increases the engine parasitic losses. One way to efficiently provide the required low-end torque and at the same time eliminate the turbo-lag is to electrify the supercharger, i.e., to replace its mechanical power source (prime mover) with an electric motor [7]-[9]. The resulting device, an electric supercharger, i.e., a motor-compressor unit (MCU), follows a popular automotive trend of vehicle electrification which has already proven capable of enhancing the efficiency and performance of numerous systems such as steering, water pump and air conditioning [10].

Historically, a lack of compact, high-power/energy-density electric sources and of light-weight, high-speed, high-powerdensity electric motors prohibited the proliferation of the MCUs throughout the automotive sector. The widely used $12 \mathrm{~V}$ battery system is at the limit of providing sufficient power for the electrical boost [4]. Besides, the high power surges from the MCU may incur high battery losses.

Today the situation regarding electric storage elements is somewhat different as a plethora of high-power batteries and high-energy capacitors has appeared on the market. However, the choice of the electric buffer technology and optimal buffer size, in terms of its power rating and energy density, is still an open question.

This paper presents a method for computing the buffer size that provides sufficient electric power and energy to run the supercharger. The supercharger is used to help the engine during

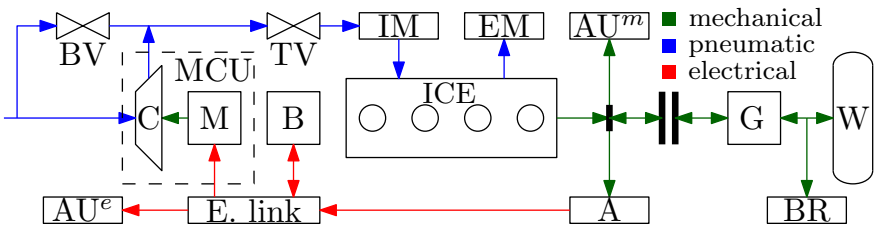

Fig. 1. Illustration of the components considered in the proposed powertrain sizing problem - arrows indicate a power flow direction. The source of air flow feeding an internal combustion engine (ICE) intake (IM) and exhaust (EM) manifolds is determined using a bypass (BV) and a throttle valve (TV). The ICE is equipped with a stand-alone motor-compressor unit (MCU) consisting of a compressor (C) and an electric motor (M). The motor, as well as other electric auxiliary loads $\left(\mathrm{AU}^{e}\right)$, draws its power from an electric buffer (B). The buffer is charged by a conventional car-alternator (A) that is mechanically coupled to the ICE crankshaft along with mechanical auxiliary loads $\left(\mathrm{AU}^{m}\right)$. A clutch and a gearbox $(\mathrm{G})$ connect the ICE with wheels (W) and brakes (BR).

short-duration high-power demands, which could potentially allow it to be downsized. Specifically, the sizing of both the ICE and the buffer is performed by minimizing the sum of the vehicle operational (fuel) and component (engine and buffer) costs. This optimization problem constitutes a dynamic program, where the ICE and buffer are optimally sized only when the vehicle is also optimally controlled on a studied driving cycle. In addition, this problem is also a non-convex, nonlinear and a mixed-integer dynamic program, where both plant design and control parameters act as optimization variables.

The plant design and control problem is typically handled by decoupling the plant and the controller, and then optimizing them sequentially or iteratively [11]-[16]. However, sequential and iterative strategies generally fail to achieve global optimality [17]. An alternative is a nested optimization strategy, where an outer loop optimizes the system objectives over a set of feasible plants, and an inner loop generates optimal controls for plants chosen by the outer loop [14]. This approach delivers a globally optimal solution, but may incur heavy computational burden (when, e.g., dynamic programming is used to optimize the energy management [18]), or may require substantial modeling approximations [19]-[21].

This paper addresses the plant design and control problem by first decoupling the integer decisions, i.e., the gear selection strategy, and then by formulating the remaining problem as a convex second order cone program (SOCP) [22]. The integer signals are decided outside of the convex program, by means of two simple heuristic strategies - one designed to promote the ICE downsizing and one that aims to maximize the ICE efficiency. Finally, a case study is provided where the optimal engine and the electric buffer sizes are computed for a specific, MCU-equipped vehicle.

This paper is organized as follows. Section II provides background to the electrically supercharged ICE configuration and states a verbal problem formulation. The mathematical modeling is provided in Section III and the convex optimization problem is formulated in Section IV. Section V presents a use-case study. Conclusions are drawn in Section VI.

\section{THE POWERTRAIN SIZING PROBLEM}

The block diagram of the electrically supercharged ICE is illustrated in Fig. 1. The MCU, which is placed in the ICE air intake along with a bypass valve, enables more power 
TABLE I

OPTIMIZATION PROBLEM FOR POWERTRAIN COMPONENTS SIZING AND ENERGY MANAGEMENT.

Minimize:
Operational + component cost,
Subject to:
Driving cycle constraints,
Energy conversion and balance constraints,
Buffer dynamics,
Physical limits of components,
$\ldots$
(For all time instances along the driving cycle).

to be delivered by the ICE, e.g., while overtaking or when starting-off at the traffic lights. The supercharging (SC) refers to a situation when the excess power is needed, i.e., when the bypass valve is closed. In contrast, during naturally-aspirated (NA) operation the bypass valve is open.

The bursts of mechanical MCU power have to be matched by the power ratings of the electric buffer that feeds the MCU. However, deciding the optimal buffer energy requirement is not trivial since it depends on the typical daily usage of the vehicle. A common way of representing the vehicle daily usage is by recording the vehicle speed and acceleration time profiles, and then by constructing a driving cycle that contains both the vehicle speed and road topography as functions of time. An example of one such cycle is the Class 3 World Harmonized Light Vehicle Test Procedure ${ }^{1}$ (WLTP3), which is used here as a proof of concept for realization of the method being proposed.

The vehicle is required to exactly follow the speed demanded by the driving cycle, thus ensuring that a possible downsizing of the powertrain does not compromise the demanded performance. To have a fair comparison, the buffer is required to sustain its initial charge at the end of the driving cycle, meaning that any energy used for supercharging has to be put back in the buffer at some point, through the use of a conventional car alternator driven by the ICE. This may require high utilization of the electric buffer, making it beneficial to increase its size. However, a larger buffer increases the cost of the vehicle. Then, to keep the cost down, the possibility of downsizing the ICE is also considered, such that the optimal trade-off is reached between the components cost and the operational cost within the lifetime of the vehicle.

The resulting optimization problem is verbally stated in Table I, whereas its mathematical description is deferred to Section IV.

\section{QUASISTATIC VEHICLE MODEL}

In the remainder, a power-based [23], quasistatic model of a 4 -stroke ICE is provided. The ICE is downsized by scaling its displacement volume while keeping its bore-stroke and compression ratios constant. Specifically, the ICE displacement volume is defined as $V_{\mathrm{E}}=s_{\mathrm{E}} \bar{V}_{\mathrm{E}}$, where $\bar{V}_{\mathrm{E}}$ denotes the baseline volume and $s_{E} \in(0,1]$ the engine scaling coefficient. The ICE is equipped with the $\mathrm{MCU}$, which provides the possibility to enhance its torque capacity by means of supercharging. To match the MCU power requirements the vehicle electric energy buffer is sized as well. For this purpose, the buffer is

\footnotetext{
${ }^{1}$ http://www.dieselnet.com/standards/cycles, March 2015.
}

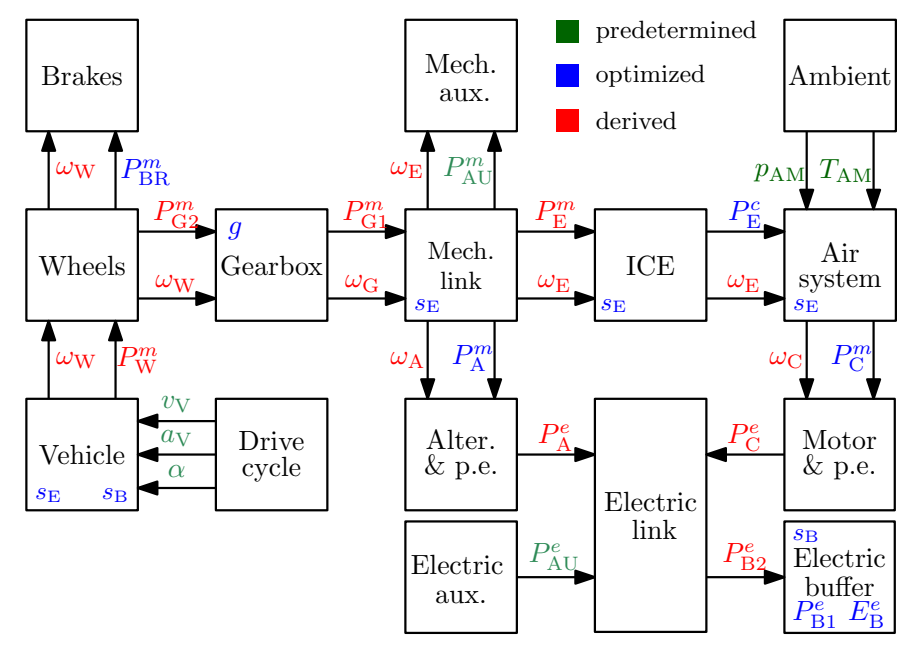

Fig. 2. Quasistatic model of an ICE equipped with a stand-alone MCU arrows indicate component inputs and outputs.

considered to be built out of $n_{\mathrm{B}}=s_{\mathrm{B}} \bar{n}_{\mathrm{B}}$ cells connected in series, where $s_{\mathrm{B}}>0$ represents the buffer scaling coefficient and $\bar{n}_{\mathrm{B}}$ the baseline cell count. Both $s_{\mathrm{E}}$ and $s_{\mathrm{B}}$ are treated as real optimization variables.

\section{A. Vehicle}

The vehicle is modeled as a system with a point mass

$$
m_{\mathrm{V}}=\bar{m}_{\mathrm{E}} s_{\mathrm{E}}+\bar{m}_{\mathrm{B}} s_{\mathrm{B}}+\bar{m}_{\mathrm{V}}
$$

where $\bar{m}_{\mathrm{E}}$ denotes the baseline engine mass, $\bar{m}_{\mathrm{B}}$ the baseline buffer mass and $\bar{m}_{\mathrm{V}}$ the baseline vehicle mass (excluding $\bar{m}_{\mathrm{E}}$ and $\bar{m}_{\mathrm{B}}$ ). The mass $\bar{m}_{\mathrm{B}}$ is further defined as $\bar{m}_{\mathrm{B}}=\bar{m}_{c} \bar{n}_{\mathrm{B}}$, with $\bar{m}_{c}$ being the baseline buffer cell mass.

If the driving cycle provides the demanded vehicle speed $\nu_{\mathrm{V}} \geq 0$, the acceleration $a_{\mathrm{V}}$ and the road slope $\alpha$, and assuming that the driving occurs in still air, the vehicle wheel speed $\omega_{\mathrm{W}}$ and the power at the wheels $P_{\mathrm{W}}^{m}$ can be computed as

$$
\begin{aligned}
\omega_{\mathrm{W}} & =\frac{\nu_{\mathrm{V}}}{r_{\mathrm{W}}}, \\
P_{\mathrm{W}}^{m} & =a_{\mathrm{V}} \lambda_{\mathrm{V}} m_{\mathrm{V}} v_{\mathrm{V}}+a_{g} \sin (\alpha) m_{\mathrm{V}} v_{\mathrm{V}}+a_{g} c_{r} \cos (\alpha) m_{\mathrm{V}} v_{\mathrm{V}} \\
& +\frac{1}{2} \rho_{\mathrm{AM}} c_{d} A_{f} v_{\mathrm{V}}^{3} .
\end{aligned}
$$

The terms on the righthand side of (3) respectively represent the inertial driving, driving on a slope, rolling resistance and aerodynamic drag power components. Here, $r_{\mathrm{W}}$ denotes the wheel radius, $\lambda_{\mathrm{V}}$ the equivalent vehicle mass ratio, $a_{g}$ the gravitational acceleration, $c_{r}$ the rolling resistance coefficient, $\rho_{\mathrm{AM}}$ the ambient air density, $c_{d}$ the drag coefficient and $A_{f}$ the vehicle's frontal area. Due to (1) the power $P_{\mathrm{W}}^{m}$ is affine in the optimization variables, i.e.,

$$
P_{\mathrm{W}}^{m}=\gamma_{\mathrm{W} 0}+\gamma_{\mathrm{W} 1} s_{\mathrm{E}}+\gamma_{\mathrm{W} 2} s_{\mathrm{B}}
$$

where

$$
\begin{aligned}
& \gamma_{\mathrm{W} 2}=\left(a_{\mathrm{V}} \lambda_{\mathrm{V}}+a_{g} \sin (\alpha)+a_{g} c_{r} \cos (\alpha)\right) \bar{m}_{\mathrm{B}} v_{\mathrm{V}} \\
& \gamma_{\mathrm{W} 1}=\left(a_{\mathrm{V}} \lambda_{\mathrm{V}}+a_{g} \sin (\alpha)+a_{g} c_{r} \cos (\alpha)\right) \bar{m}_{\mathrm{E}} v_{\mathrm{V}} \\
& \gamma_{\mathrm{W} 0}=\frac{1}{2} \rho_{\mathrm{AM}} c_{d} A_{f} \nu_{\mathrm{V}}^{3}+\left(a_{\mathrm{V}} \lambda_{\mathrm{V}}+a_{g} \sin (\alpha)+a_{g} c_{r} \cos (\alpha)\right) \bar{m}_{\mathrm{V}} v_{\mathrm{V}}
\end{aligned}
$$




\section{B. Wheels \& brakes}

The required mechanical power at the wheel side of the gearbox is given by

$$
P_{\mathrm{G} 2}^{m}=P_{\mathrm{W}}^{m}+P_{\mathrm{BR}}^{m},
$$

where $P_{\mathrm{BR}}^{m} \geq 0$ is an optimization variable representing the power of the brakes.

\section{Gearbox}

The speed and power at the engine side of the gearbox are given by the following expressions

$$
\begin{aligned}
\omega_{\mathrm{G}} & =\lambda_{\mathrm{G}}(g) \omega_{\mathrm{W}}, \\
P_{\mathrm{G} 1}^{m} & =\gamma_{\mathrm{G} 0}+P_{\mathrm{G} 2}^{m},
\end{aligned}
$$

where

$$
\gamma_{\mathrm{G} 0}=c_{\mathrm{G} 0}+c_{\mathrm{G} 1} \omega_{\mathrm{G}}+c_{\mathrm{G} 2} \omega_{\mathrm{G}}^{2},
$$

with $\lambda_{\mathrm{G}}(g)$ denoting the gear ratio corresponding to the gear $g \in\{1, \ldots, 5\}$ and $\gamma_{\mathrm{G} 0} \geq 0$ the gearbox drag losses. The gear is treated as an optimization variable decided separately and prior to the rest, see Section IV-B.

\section{Mechanical power link}

To be able to distinguish between regular and idling engine operation, define

$$
\gamma_{\mathrm{ML}}= \begin{cases}1, & \text { for } \omega_{\mathrm{G}} \geq \omega_{\mathrm{E}, \min }, \\ 0, & \text { otherwise }\end{cases}
$$

Then the engine and the alternator speed exiting the mechanical power link follow

$$
\begin{aligned}
& \omega_{\mathrm{E}}=\omega_{\mathrm{G}} \gamma_{\mathrm{ML}}+\omega_{\mathrm{E}, \min }\left(1-\gamma_{\mathrm{ML}}\right), \\
& \omega_{\mathrm{A}}=\lambda_{\mathrm{A}} \omega_{\mathrm{E}},
\end{aligned}
$$

while the corresponding engine mechanical power balance reads

$$
P_{\mathrm{E}}^{m}=P_{\mathrm{G} 1}^{m} \gamma_{\mathrm{ML}}+P_{\mathrm{A}}^{m}+P_{\mathrm{AU}}^{m} .
$$

Here, $\lambda_{\mathrm{A}}$ denotes the alternator speed ratio, $\omega_{\mathrm{E}}$ and $\omega_{\mathrm{E}, \min }$ the ICE rotational and idle speed, $\omega_{\mathrm{A}}$ the alternator speed, and $P_{\mathrm{E}}^{m}, P_{\mathrm{A}}^{m}, P_{\mathrm{AU}}^{m} \geq 0$ the mechanical power of the ICE, alternator and the remaining mechanical auxiliary units (assumed constant). The power $P_{\mathrm{A}}^{m}$ is one of the optimization variables.

\section{E. ICE \& air-fuel control}

The ICE mechanical behavior can be described using the following relationship [24], [25]:

$$
\bar{p}_{\mathrm{E}}=\bar{\eta}_{\mathrm{E}} \bar{p}_{\phi}-\bar{p}_{\mathrm{Ef}}-\bar{p}_{\mathrm{Eg}},
$$

where $\bar{\eta}_{\mathrm{E}}$ denotes the effective ICE efficiency, $\bar{p}_{\mathrm{E}}$ and $\bar{p}_{\phi}$ the engine brake and fuel mean effective pressures, and $\bar{p}_{\mathrm{Ef}}$ and $\bar{p}_{\text {Eg }}$ the brake mean effective pressure losses due to engine friction and pumping work. Assuming that the ratio $\lambda_{e c}$, the ignition/injection timing angles, the burnt gas fraction and the bore-stroke ratio are kept constant, the effective efficiency $\bar{\eta}_{\mathrm{E}}$ can be treated as a function of the engine speed only [24], i.e.,

$$
\bar{\eta}_{\mathrm{E}}=c_{\bar{\eta} 0}+c_{\bar{\eta} 1} \omega_{\mathrm{E}}+c_{\bar{\eta} 2} \omega_{\mathrm{E}}^{2},
$$

where $c_{\bar{\eta} i}, i \in\{0,1,2\}$ denote constant parameters. The two pressures, $\bar{p}_{\mathrm{E}}$ and $\bar{p}_{\phi}$, further read

$$
\begin{aligned}
& \bar{p}_{\mathrm{E}}=\frac{4 \pi \tau_{\mathrm{E}}}{\bar{V}_{\mathrm{E}} s_{\mathrm{E}}} \\
& \bar{p}_{\phi}=\frac{4 \pi P_{\mathrm{E}}^{c}}{\bar{V}_{\mathrm{E}} \omega_{\mathrm{E}} s_{\mathrm{E}}},
\end{aligned}
$$

while the related loss components may be modeled $^{2}[24]$ as

$$
\begin{aligned}
& \bar{p}_{\mathrm{Ef}}=c_{f 0}+c_{f 2} \omega_{\mathrm{E}}^{2}, \\
& \bar{p}_{\mathrm{Eg}}=c_{g 0}+c_{g 1} \frac{\tau_{\mathrm{E}}}{\tau_{\mathrm{E}, \max }},
\end{aligned}
$$

with $\tau_{\mathrm{E}, \max }=\tau_{\mathrm{E}, \max }\left(\omega_{\mathrm{E}}, s_{\mathrm{E}}\right)$ denoting the maximum achievable torque $\tau_{\mathrm{E}}$ of a downsized ICE during its NA operation, $c_{f 0}, c_{f 2}, c_{g 0}$ and $c_{g 1}$ some constant parameters. The ICE chemical (fuel) power $P_{\mathrm{E}}^{c}$ is given by

$$
P_{\mathrm{E}}^{c}=\dot{m}_{\phi} H_{l},
$$

with $H_{l}$ being the fuel lower heating value and $\dot{m}_{\phi}$ the ICE fuel mass flow. Assuming that the fuel controller maintains a constant, stoichiometric air-fuel ratio $\lambda_{\alpha \phi}$, the flow $\dot{m}_{\phi}$ is related to the required engine air mass flow as

$$
\dot{m}_{\phi}=\frac{\dot{m}_{\alpha}}{\lambda_{\alpha \phi}} .
$$

Since from the air system perspective the engine acts as a volumetric pump, the air mass flow fulfills

$$
\dot{m}_{\alpha}=\eta_{\mathrm{vol}} \frac{p_{\mathrm{AM}} s_{\mathrm{E}} \bar{V}_{\mathrm{E}} \omega_{\mathrm{E}} \lambda_{\Pi}}{4 \pi c_{R} T_{\mathrm{IM}}},
$$

where $\lambda_{\Pi}$ represents the ratio between the intake manifold and the ambient air pressures, $p_{\mathrm{IM}}$ and $p_{\mathrm{AM}}$, satisfying $0 \leq \lambda_{\Pi} \leq$ $\lambda_{\Pi, \max }>1$, with $\lambda_{\Pi, \max }$ being its stoichiometric combustion knock limit value. Furthermore, $c_{R}$ is the specific gas constant of air, $T_{\mathrm{IM}}$ the intake manifold air temperature and $\eta_{\mathrm{vol}}=$ $\eta_{\mathrm{vol}}\left(\omega_{\mathrm{E}}, \lambda_{\Pi}\right)$ the engine volumetric efficiency. The efficiency $\eta_{\mathrm{vol}}$ is frequently modeled as a multilinear function [24] of the pressure ratio $\lambda_{\Pi}$ and the speed $\omega_{\mathrm{E}}$, i.e.,

$$
\eta_{\mathrm{vol}}=\eta_{\mathrm{vol}, \omega} \eta_{\mathrm{vol}, \Pi}
$$

where

$$
\begin{aligned}
& \eta_{\mathrm{vol}, \omega}=c_{\mathrm{vol} 0}+c_{\mathrm{vol} 1} \omega_{\mathrm{E}}+c_{\mathrm{vol} 2} \omega_{\mathrm{E}}^{2} \\
& \eta_{\mathrm{vol}, \Pi}=1+\frac{1}{\lambda_{e c}}\left(1-\left(\frac{p_{\mathrm{EM}}}{p_{\mathrm{AM}}}\right)^{1 / \lambda_{\kappa}} \lambda_{\Pi}^{-1 / \lambda_{\kappa}}\right),
\end{aligned}
$$

with $p_{\mathrm{EM}}$ being the (constant) exhaust manifold pressure, $\lambda_{e c}$ the engine compression ratio, $\lambda_{\kappa}$ the specific heat ratio of air and $c_{\mathrm{voli}}, i \in\{0,1,2\}$ some constant parameters.

Using (16) to (21) the expression (14) can be rewritten in terms of torque, as follows

$$
\tau_{\mathrm{E}}=\bar{\eta}_{\mathrm{E}} \frac{\dot{m}_{\alpha} H_{l}}{\lambda_{\alpha \phi} \omega_{\mathrm{E}}}-\frac{\bar{V}_{\mathrm{E}} s_{\mathrm{E}}}{4 \pi}\left(\bar{p}_{\mathrm{Ef}}+c_{g 0}+c_{g 1} \frac{\tau_{\mathrm{E}}}{\tau_{\mathrm{E}, \max }}\right) .
$$

Since during the ICE NA operation at a wide-open throttle it holds $\tau_{\mathrm{E}}=\tau_{\mathrm{E}, \max }\left(\omega_{\mathrm{E}}, s_{\mathrm{E}}\right), \lambda_{\Pi} \approx 1$ and $T_{\mathrm{IM}} \approx T_{\mathrm{AM}}$, where $T_{\mathrm{AM}}$ denotes the ambient air temperature - by substituting these

\footnotetext{
${ }^{2}$ The adopted friction loss model is pessimistic as lower friction losses can be expected in the case of downsized engines.
} 
values and the flow given by (22) in (25), the expression for torque $\tau_{\mathrm{E}, \max }$ can be derived. This yields

$$
\begin{aligned}
\tau_{\mathrm{E}, \max } & =\left(\bar{\eta}_{\mathrm{E}} \bar{\eta}_{\mathrm{vol}} \frac{p_{\mathrm{AM}} \bar{V}_{\mathrm{E}} H_{l}}{4 \pi c_{R} T_{\mathrm{AM}} \lambda_{\alpha \phi}}-\frac{\bar{V}_{\mathrm{E}}\left(\bar{p}_{\mathrm{Ef}}+c_{g 0}+c_{g 1}\right)}{4 \pi}\right) s_{\mathrm{E}} \\
& =\bar{\tau}_{\mathrm{E}, \max s_{\mathrm{E}}}
\end{aligned}
$$

where $\bar{\tau}_{\mathrm{E}, \max }=\bar{\tau}_{\mathrm{E}, \max }\left(\omega_{\mathrm{E}}\right)$ denotes the maximum achievable torque of a baseline (non-downsized) NA ICE and $\bar{\eta}_{\mathrm{vol}}=$ $\eta_{\mathrm{vol}}\left(\omega_{\mathrm{E}}, 1\right)$. By multiplying both sides of (25) with $\omega_{\mathrm{E}}$ and using (27), one can further obtain the relationship between the ICE mechanical $P_{\mathrm{E}}^{m}=\tau_{\mathrm{E}} \omega_{\mathrm{E}}$ and the fuel power $P_{\mathrm{E}}^{c}$, i.e.,

$$
\begin{aligned}
& P_{\mathrm{E}}^{c}=\frac{4 \pi \bar{\tau}_{\mathrm{E}, \max }+c_{g 1} \bar{V}_{\mathrm{E}}}{4 \pi \bar{\tau}_{\mathrm{E}, \max } \bar{\eta}_{\mathrm{E}}} P_{\mathrm{E}}^{m}+\frac{\bar{V}_{\mathrm{E}} \omega_{\mathrm{E}}\left(\bar{p}_{\mathrm{Ef}}+c_{g 0}\right)}{4 \pi \bar{\eta}_{\mathrm{E}}} s_{\mathrm{E}}, \\
& P_{\mathrm{E}}^{c}=\gamma_{\mathrm{E} 1} P_{\mathrm{E}}^{m}+\gamma_{\mathrm{E}, \min s_{\mathrm{E}}},
\end{aligned}
$$

where $\gamma_{\mathrm{E} 1}>1$ and $\gamma_{\mathrm{E}, \min }>0$. The power $P_{\mathrm{E}}^{c}$ is treated as an optimization variable.

\section{F. Air system}

During the ICE SC operation it holds $\tau_{\mathrm{E}}>\tau_{\mathrm{E}, \max }\left(\omega_{\mathrm{E}}, s_{\mathrm{E}}\right)$, when $p_{\mathrm{IM}} \approx p_{\mathrm{C}}>p_{\mathrm{AM}}$ and $T_{\mathrm{IM}} \approx T_{\mathrm{C}}>T_{\mathrm{AM}}$, where $p_{\mathrm{C}}, T_{\mathrm{C}}$ denote the compressor outlet pressure and temperature. Thus one may approximate the compressor pressure ratio $p_{\mathrm{C}} / p_{\mathrm{AM}}$ by the intake manifold pressure ratio $\lambda_{\Pi}$ and express the temperature $T_{\mathrm{C}}$, as

$$
T_{\mathrm{C}}=T_{\mathrm{AM}}+\frac{T_{\mathrm{AM}}}{\eta_{\mathrm{C}}}\left(\lambda_{\Pi}^{\frac{\lambda_{K}-1}{\lambda_{K}}}-1\right),
$$

where $\eta_{\mathrm{C}}$ is the isentropic compressor efficiency (assumed constant). The equations (22) and (30) uniquely determine the values of $T_{\mathrm{C}}$ and $\lambda_{\Pi}$ for each given $\dot{m}_{\alpha}$ and $\omega_{\mathrm{E}}$. Although the underlying relations are nonlinear in $\lambda_{\Pi}$, in its narrow range of interest, i.e., for $\lambda_{\Pi} \in\left[1, \lambda_{\Pi, \max }\right]$, they can be approximated by suitable affine functions. To achieve this, the expressions (22) and (30) are first rewritten as

$$
\begin{aligned}
T_{\mathrm{C}} & =\lambda_{T} T_{\mathrm{AM}}, \\
\dot{m}_{\alpha} & =\lambda_{\dot{m}} \gamma_{\dot{m}} s_{\mathrm{E}},
\end{aligned}
$$

where $\lambda_{T}=1+\frac{1}{\eta_{\mathrm{C}}}\left(\lambda_{\Pi}^{\frac{\lambda_{\kappa}-1}{\lambda_{\kappa}}}-1\right), \lambda_{\dot{m}}=\frac{\eta_{\mathrm{vol}, \Pi} \lambda_{\Pi}}{\lambda_{T}}$ and $\gamma_{\dot{m}}=$ $\frac{p_{\mathrm{AM}} \bar{V}_{\mathrm{E}} \omega_{\mathrm{E}} \eta_{\mathrm{vol}, \omega}}{4 \pi c_{R} T_{\mathrm{AM}}}$. Then, the best affine fits $\hat{\lambda}_{T} \approx \lambda_{T}$ and $\hat{\lambda}_{\dot{m}} \approx \lambda_{\dot{m}}$ (w.r.t. $\lambda_{\Pi}$, in the least-squares sense) are constructed while enforcing $\hat{\lambda}_{T}(1)=\lambda_{T}(1)$ and $\hat{\lambda}_{\dot{m}}(1)=\lambda_{\dot{m}}(1)$, to preserve continuity. This yields

$$
\begin{aligned}
& \hat{\lambda}_{T}=c_{T 0}+c_{T 1} \lambda_{\Pi}, \\
& \hat{\lambda}_{\dot{m}}=c_{\dot{m} 0}+c_{\dot{m} 1} \lambda_{\Pi},
\end{aligned}
$$

where $c_{T i}>0$ and $c_{m i}>0, i \in\{0,1\}$ are constant parameters, see Fig. 3.

From (31), (33), (21) and (20) the pressure ratio limit $\lambda_{\Pi} \leq$ $\lambda_{\Pi, \max }$ can be expressed as an engine size-dependent limit on the fuel power $P_{\mathrm{E}}^{c}$. Specifically, it follows

$$
P_{\mathrm{E}}^{c} \leq \frac{\gamma_{\dot{m}} H_{l}\left(c_{\dot{m} 0}+c_{\dot{m} 1} \lambda_{\Pi, \max }\right)}{\lambda_{\alpha \phi}} s_{\mathrm{E}}=\gamma_{\mathrm{E}, \max } s_{\mathrm{E}} .
$$

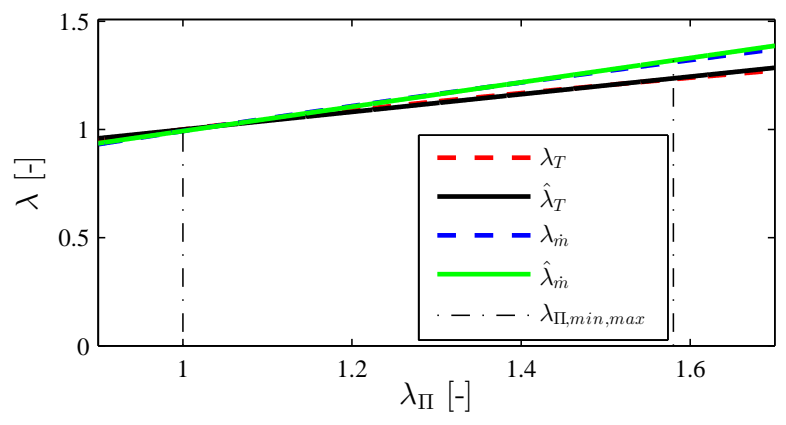

Fig. 3. Affine approximation of compressor temperature $T_{\mathrm{C}}$ and engine air mass flow $\dot{m}_{\alpha}$ dependence on the intake manifold pressure ratio $\lambda_{\Pi}$.

Furthermore, the mechanical $\mathrm{MCU}$ power $P_{\mathrm{C}}^{m} \leq c_{\mathrm{C}, \max }$, is given by

$$
P_{\mathrm{C}}^{m}=\max \left(\dot{m}_{\alpha} c_{p}\left(T_{\mathrm{C}}-T_{\mathrm{AM}}\right), 0\right),
$$

where $c_{p}$ denotes the specific heat of air at constant pressure and $c_{\mathrm{C}, \max }$ the maximum compressor mechanical power (assumed constant). Using (31), (32), (21) and (20), the power $P_{\mathrm{C}}^{m}$ can be computed as

$$
P_{\mathrm{C}}^{m}=\max \left(c_{\mathrm{C} 1} P_{\mathrm{E}}^{c}+\gamma_{\mathrm{C} 2} \frac{P_{\mathrm{E}}^{c 2}}{s_{\mathrm{E}}}, 0\right),
$$

with the coefficients

$$
\begin{aligned}
c_{\mathrm{C} 1} & =\frac{\lambda_{\alpha \phi} c_{p} T_{\mathrm{AM}}\left(c_{T 0} c_{\dot{m} 1}-c_{T 1} c_{\dot{m} 0}-c_{\dot{m} 1}\right)}{H_{l} c_{\dot{m} 1}}, \\
\gamma_{\mathrm{C} 2} & =\frac{\lambda_{\alpha \phi}^{2} c_{p} T_{\mathrm{AM}} c_{T 1}}{H_{l}^{2} c_{\dot{m} 1} \gamma_{\dot{m}}} .
\end{aligned}
$$

Since $\gamma_{\mathrm{C} 2}>0, \forall \omega_{\mathrm{E}}$, the expression $\gamma_{\mathrm{C} 2} P_{\mathrm{E}}^{c 2}+c_{\mathrm{C} 1} P_{\mathrm{E}}^{c}$ is convex in $P_{\mathrm{E}}^{c}$. Moreover, as $s_{\mathrm{E}}>0$, a perspective function [22] corresponding to this expression is given by the first argument of the maximum function in (36), which implies that this argument is convex in both $P_{\mathrm{E}}^{c}$ and $s_{\mathrm{E}}$. Because the maximum of two convex functions is itself convex, the same also holds for the compressor power $P_{\mathrm{C}}^{m}$.

Furthermore, it is assumed that for the air mass flow/pressure ratio range of interest the MCU can be always chosen such that the compressor surge/choke phenomena do not occur. The surge condition can be expressed as [24]:

$$
\omega_{\mathrm{C}} \leq \omega_{\mathrm{C}, \text { surge }} \approx c_{\text {surge } 0}+c_{\text {surge } 1} \dot{m}_{\alpha},
$$

where $\omega_{\mathrm{C}}$ denotes the compressor speed, $\omega_{\mathrm{C} \text {,surge }}\left(\dot{m}_{\alpha}\right)$ the compressor surge speed limit (for a given air mass flow) and $c_{\text {surge } 0}, c_{\text {surge } 1}>0$ some constant fitting coefficients.

\section{G. Alternator and MCU motor}

The electric machine electric power can be modeled as a second-order polynomial of its mechanical power, with a constant term representing a speed-dependent drag loss [25]. In this context, the alternator electric power can be formulated as

$$
P_{\mathrm{A}}^{e}=\gamma_{\mathrm{A} 0}+c_{\mathrm{A} 1} P_{\mathrm{A}}^{m}+c_{\mathrm{A} 2} P_{\mathrm{A}}^{m 2},
$$

where

$$
\gamma_{\mathrm{A} 0}=c_{\mathrm{A} 00}+c_{\mathrm{A} 01} \omega_{\mathrm{A}}+c_{\mathrm{A} 02} \omega_{\mathrm{A}}^{2}>0
$$



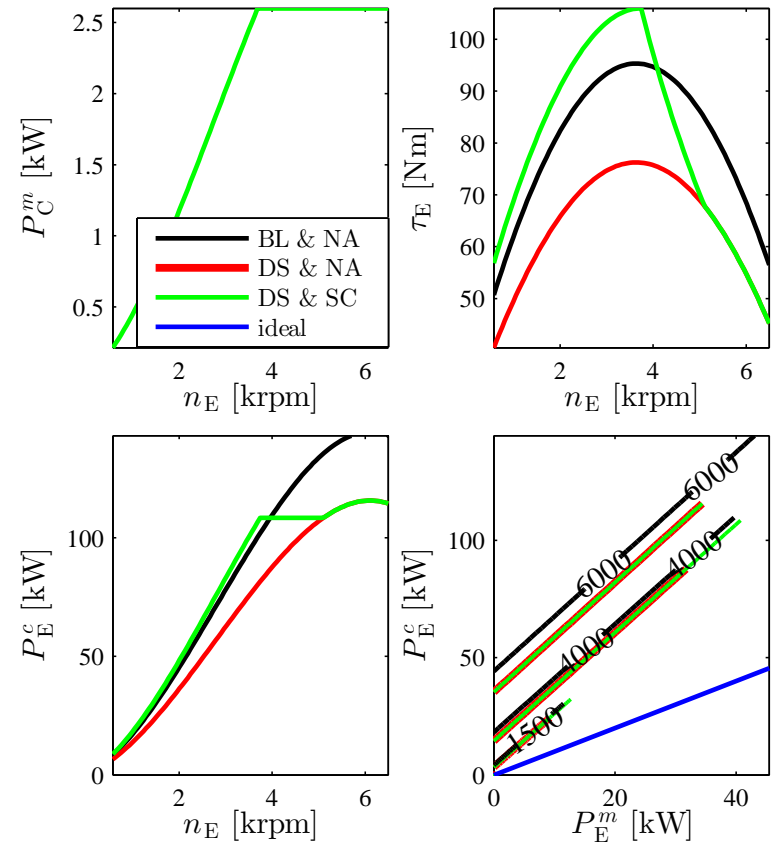

Fig. 4. Top left: the constrained compressor power $P_{\mathrm{C}}^{m}$ needed to achieve the maximum pressure ratio $\lambda_{\Pi, \max }=1.58$. Top right: the maximum ICE torque $\tau_{\mathrm{E}}$ of the baseline NA, the downsized NA and the downsized SC ICE (with $s_{\mathrm{E}}=0.8, \lambda_{\Pi \text { max }}=1.58$ ). Bottom left: the corresponding maximum ICE chemical power $P_{\mathrm{E}}^{c}$. Bottom right: the ICE chemical power $P_{\mathrm{E}}^{c}$ vs. the ICE mechanical power $P_{E}^{m}$. The speed $n_{\mathrm{E}}$ represents the ICE speed $\omega_{\mathrm{E}}$ expressed in (thousands of) rotations per minute.

with $c_{\mathrm{A} 0 i}, i \in\{0,1,2\}, c_{\mathrm{A} 02} \geq 0,-1<c_{\mathrm{A} 1}<0$ and $c_{\mathrm{A} 2} \geq 0$ being constant coefficients, see Fig. 5. The signs of $c_{\mathrm{A} 1}$ and $c_{\mathrm{A} 2}$ ensure that the electric alternator power $P_{\mathrm{A}}^{e}$ is nonpositive for a non-negative mechanical alternator power $P_{\mathrm{A}}^{m}$. This is in accordance with a general convention (in the energy management of electrified vehicles) which states that the electric power should be positive when the electric machine acts to discharge the electric buffer (i.e., during motoring) and negative when it charges it (i.e., during generating). Furthermore, the coefficient $c_{\mathrm{A} 1}$ is bounded to reflect the physical limitations of the alternator. Namely, if one would let $c_{\mathrm{A} 1}>=0$ this would imply that the alternator can sometimes operate as a motor, which is not considered in this study. If, however, $c_{\mathrm{A} 1}<=-1$, then it could happen that the alternator electrical power output is absolutely larger than its mechanical power input, which is not physically possible.

The mechanical power $P_{\mathrm{A}}^{m}$ is constrained both above and below, i.e., $0 \leq \gamma_{\mathrm{A}, \min } \leq P_{\mathrm{A}}^{m} \leq c_{\mathrm{A}, \max }$, where

$$
\gamma_{\mathrm{A}, \text { min }}=\frac{-c_{\mathrm{A} 1}-\sqrt{c_{\mathrm{A} 1}^{2}-4 \gamma_{\mathrm{A} 0} c_{\mathrm{A} 2}}}{2 c_{\mathrm{A} 2}}
$$

and $c_{\mathrm{A}, \max }$ is a constant parameter.

Similarly to the alternator, the MCU electric power $P_{\mathrm{C}}^{e}$ can be modeled as

$$
P_{\mathrm{C}}^{e}=P_{\mathrm{C} 0}^{m}+c_{\mathrm{M} 1} P_{\mathrm{C}}^{m}+c_{\mathrm{M} 2} P_{\mathrm{C}}^{m 2},
$$

where the speed-dependent motor drag loss is given by

$$
P_{\mathrm{C} 0}^{m}=\bar{c}_{\mathrm{M} 00}+\bar{c}_{\mathrm{M} 01} \omega_{\mathrm{C}}+\bar{c}_{\mathrm{M} 02} \omega_{\mathrm{C}}^{2}>0,
$$

with $\bar{c}_{\mathrm{M} 0 i}, i \in\{0,1,2\}, \bar{c}_{\mathrm{M} 02} \geq 0, c_{\mathrm{M} 1}>1$ and $c_{\mathrm{M} 2} \geq 0$ being constant coefficients [25]. The motor drag loss $P_{\mathrm{C} 0}^{m}$ can be upper-bounded by setting $\omega_{\mathrm{C}}=\omega_{\mathrm{C} \text {,surge }}$, which from (20), (21) and (38) yields

$$
P_{\mathrm{C} 0}^{m}=c_{\mathrm{M} 00}+c_{\mathrm{M} 01} P_{\mathrm{E}}^{c}+c_{\mathrm{M} 02} P_{\mathrm{E}}^{c 2},
$$

with the coefficients

$$
\begin{aligned}
c_{\mathrm{M} 00} & =\bar{c}_{\mathrm{M} 00}+\bar{c}_{\mathrm{M} 01} c_{\text {surge } 0}+\bar{c}_{\mathrm{M} 02} c_{\text {surge } 0}^{2}, \\
c_{\mathrm{M} 01} & =\frac{\lambda_{\alpha \phi}}{H_{l}}\left(\bar{c}_{\mathrm{M} 01} c_{\text {surge } 1}+2 \bar{c}_{\mathrm{M} 02} c_{\text {surge } 0} c_{\text {surge } 1}\right), \\
c_{\mathrm{M} 02} & =\frac{\lambda_{\alpha \phi}^{2}}{H_{l}^{2}} \bar{c}_{\mathrm{M} 02} c_{\text {surge } 1}^{2} .
\end{aligned}
$$

Note that since $c_{\mathrm{M} 02} \geq 0$ the drag loss $P_{\mathrm{C} 0}^{m}$ is convex w.r.t. the fuel power $P_{\mathrm{E}}^{c}$. In the same way, the compressor electric power $P_{\mathrm{C}}^{e}$ is convex w.r.t. both its mechanical power $P_{\mathrm{C}}^{m}$ and fuel power $P_{\mathrm{E}}^{c}$, and the alternator electric power $P_{\mathrm{A}}^{e}$ is convex w.r.t. its mechanical power $P_{\mathrm{A}}^{m}$.

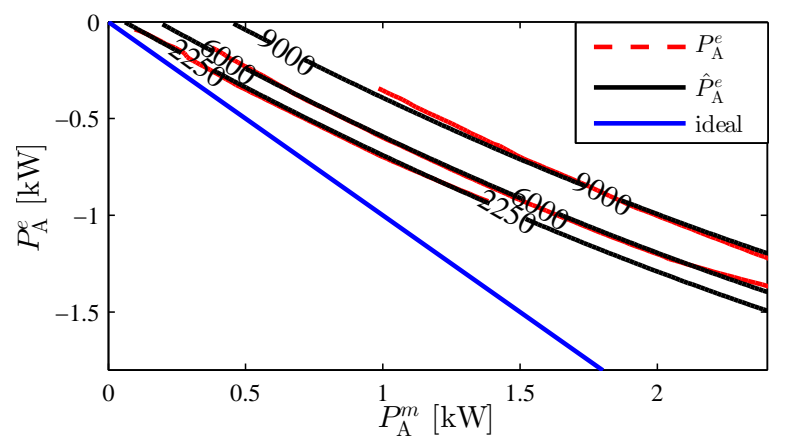

Fig. 5. Convex approximation of the alternator electric power $P_{\mathrm{A}}^{e}$ as a function of its mechanical power $P_{\mathrm{A}}^{m}$ and speed $\omega_{\mathrm{A}}$.

\section{H. Electric power link}

The electric buffer terminal power follows from the power balance at the electric power link, given by

$$
P_{\mathrm{B} 2}^{e}=P_{\mathrm{A}}^{e}+P_{\mathrm{C}}^{e}+P_{\mathrm{AU}}^{e},
$$

where $P_{\mathrm{AU}}^{e} \geq 0$ is the power consumed by electric auxiliary devices (assumed constant).

\section{Electric buffer}

The electric buffer cells are considered to be either lithiumion batteries, or supercapacitors. Each cell is modeled as a cell open circuit voltage $u_{c}$ with a constant resistance $R_{c}$ connected in series. The voltage $u_{c}$ is modeled as an affine function of state-of-charge $\operatorname{soc} \in[0,1]$, i.e.,

$$
u_{c}=\frac{Q_{c}}{c_{c 1}} \operatorname{soc}+c_{c 0},
$$

where $Q_{c}$ is the cell capacity, and $c_{c 1}$ and $c_{c 0}$ are the resulting fitting coefficients. Such a model is suitable for lithium-ion battery technology, see Fig. 6, where low/high soc operation is avoided due to battery longevity reasons [26].

As $n_{\mathrm{B}}$ cells are connected in series, the buffer terminal voltage $u_{\mathrm{B} 2}$ reads

$$
u_{\mathrm{B} 2}=n_{\mathrm{B}} u_{c}-n_{\mathrm{B}} R_{c} i_{c},
$$




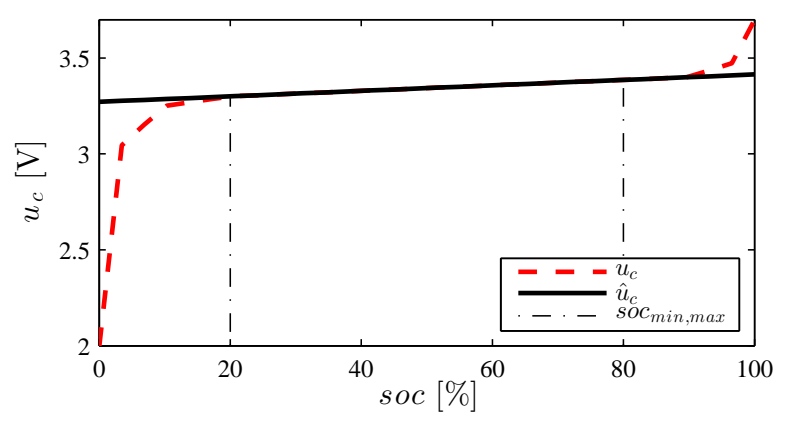

Fig. 6. Battery cell open circuit voltage.

where $i_{c}$ denotes the cell current, which determines the evolution of the cell state-of-charge, i.e.,

$$
\frac{\mathrm{d} s o c}{\mathrm{~d} t}=-\frac{i_{c}}{Q_{c}} .
$$

In the following, convex modeling steps of [27] were employed, where instead of using $u_{c}$ and $i_{c}$ the electric buffer is modeled in terms of its energy $E_{\mathrm{B}}^{e}$, internal power $P_{\mathrm{B} 1}^{e}$, dissipative power $P_{\mathrm{B} 0}^{e}$ and terminal power $P_{\mathrm{B} 2}^{e}$. In this context $P_{\mathrm{B} 1}^{e}$ and $E_{\mathrm{B}}^{e}$ are treated as the additional (although constrained) optimization variables. Specifically, the energy reads

$$
\frac{\mathrm{d} E_{\mathrm{B}}^{e}}{\mathrm{~d} t}=-P_{\mathrm{B} 1}^{e},
$$

meaning that $P_{\mathrm{B} 1}^{e}>0$ results in buffer discharge and vice versa. The internal and dissipative buffer powers are defined as

$$
\begin{aligned}
& P_{\mathrm{B} 1}^{e}=n_{\mathrm{B}} u_{c} i_{c}, \\
& P_{\mathrm{B} 0}^{e}=n_{\mathrm{B}} R_{c} i_{c}^{2} .
\end{aligned}
$$

This implies

$$
P_{\mathrm{B} 1}^{e}=P_{\mathrm{B} 2}^{e}+P_{\mathrm{B} 0}^{e} .
$$

Furthermore, from (49), (50) and (51), it follows

$$
E_{\mathrm{B}}^{e}=n_{\mathrm{B}} Q_{c} \int_{0}^{s o c} u_{c}(s) d s=\frac{n_{\mathrm{B}} c_{c 1}}{2}\left(u_{c}^{2}-c_{c 0}^{2}\right) .
$$

Thus the pack losses may be expressed as

$$
P_{\mathrm{B} 0}^{e}=\frac{R_{c} c_{c 1} P_{\mathrm{B} 1}^{e 2}}{2 E_{\mathrm{B}}^{e}+n_{\mathrm{B}} c_{c 1} c_{c 0}^{2}},
$$

which, as a quadratic-over-linear, with a strictly positive denominator, is a convex function [22] of $P_{\mathrm{B} 1}^{e}, E_{\mathrm{B}}^{e}$ and $n_{\mathrm{B}}$ (and therefore also $s_{\mathrm{B}}$ ). Note that when $c_{c 0}=0$ the adopted model, (53) and (54), describes a capacitor with a capacitance $c_{c 1}$.

Constraints on the state $s o c$ and the current $i_{c}$ can be translated into constraints on the energy $E_{\mathrm{B}}^{e}$ and the power $P_{\mathrm{B} 1}^{e}$, i.e.,

$$
\begin{aligned}
& E_{\mathrm{B}}^{e} \in \frac{n_{\mathrm{B}} c_{c 1}}{2}\left(\left[u_{c}^{2}\left(\operatorname{soc}_{\text {min }}\right), u_{c}^{2}\left(\operatorname{soc}_{\text {max }}\right)\right]-c_{c 0}^{2}\right) \\
& =\left[\bar{E}_{\mathrm{B}, \text { min }}^{e}, \bar{E}_{\mathrm{B}, \text { max }}^{e}\right] s_{\mathrm{B}}, \\
& P_{\mathrm{B} 1}^{e} \in\left[i_{c, \text { min }}, i_{c, \text { max }}\right] \sqrt{n_{\mathrm{B}}\left(\frac{2 E_{\mathrm{B}}^{e}}{c_{c 1}}+n_{\mathrm{B}} c_{c 0}^{2}\right)},
\end{aligned}
$$

where $\operatorname{soc}_{\min }$ and soc $_{\max }$ represent the minimum and the maximum state-of-charge, $i_{c, \min }<0$ and $i_{c, \max }>0$ the minimum and the maximum cell current and $\bar{E}_{\mathrm{B}, \text { min }}^{e}$ and $\bar{E}_{\mathrm{B}, \max }^{e}$ the baseline minimum and the maximum buffer energy. Notice that the geometric mean in (56) is a concave function [22] of $E_{\mathrm{B}}^{e}$ and $n_{\mathrm{B}}$.

\section{OPTIMIZATION PROBLEM FORMULATION}

The optimization problem formulated in Table I is revisited here by providing mathematical meaning to constraints and the objective function. In this context, the optimization goal is defined as finding the minimum of a weighted sum of operational and component costs. The former is simply represented by the cost of consumed petroleum while the latter consists of a sum of the ICE and the electric buffer cost. Each specific cost component is weighted by its respective weighting coefficient, $w_{\phi}, w_{\mathrm{E}}$ or $w_{\mathrm{B}}$, so that its contribution is expressed in currency per distance. Using the approach outlined in [28] these coefficients can be computed as

$$
\begin{aligned}
& w_{\phi}=\mu_{\phi} \frac{1}{H_{l} \rho_{\phi} d}, \\
& w_{\mathrm{E}}=\mu_{\mathrm{E}} \frac{\bar{P}_{\mathrm{E}, \text { max }}^{m}}{d_{\text {year }}} \frac{t_{\text {year }}}{t_{\text {life }}}\left(1+\varepsilon_{\mathrm{E}, \text { year }} \frac{t_{\text {life }}+1}{2}\right), \\
& w_{\mathrm{B}}=\mu_{B} \frac{\bar{E}_{\mathrm{B}, \text { max }}^{e}}{d_{\text {year }}} \frac{t_{\text {year }}}{t_{\text {life }}}\left(1+\varepsilon_{\mathrm{B}, \text { year }} \frac{t_{\text {life }}+1}{2}\right) .
\end{aligned}
$$

where $\mu_{\phi}, \mu_{\mathrm{E}}$ and $\mu_{\mathrm{B}}$ are fuel, engine and buffer price expressed respectively in currency per volume, power and energy. Furthermore, $d=\int_{0}^{t_{\text {end }}} v_{\mathrm{V}} d t$ is the total drive cycle length, $d_{\text {year }}$ the average distance a vehicle travels during one year $t_{\text {year }}, \rho_{\phi}$ the fuel density, $\bar{P}_{\mathrm{E}, \max }^{m}=\max _{\omega_{\mathrm{E}}} \bar{\tau}_{\mathrm{E}, \max } \omega_{\mathrm{E}}$ the maximum baseline NA ICE mechanical power, $t_{\text {life }}$ the duration of the expected vehicle life-cycle, and $\varepsilon_{\mathrm{E}, \mathrm{year}}$ and $\varepsilon_{\mathrm{B}, \text { year }}$ the yearly engine and buffer interest rates.

\section{A. Convex optimization problem}

Based on the equations derived in the previous section the related optimization problem is summarized as follows

$$
\begin{aligned}
& \min J=w_{\phi} \int_{0}^{t_{\text {end }}} P_{\mathrm{E}}^{c} d t+w_{\mathrm{E}} s_{\mathrm{E}}+w_{\mathrm{B}} s_{\mathrm{B}}, \\
& \text { s.t. }(55),(56) \text {, } \\
& 0<s_{\mathrm{B}}, \quad 0<s_{\mathrm{E}} \leq 1, \quad 0 \leq P_{\mathrm{BR}}^{m}, \quad P_{\mathrm{C}}^{m} \leq c_{\mathrm{C}, \max }, \\
& \gamma_{\mathrm{A}, \min } \leq P_{\mathrm{A}}^{m} \leq c_{\mathrm{A}, \max }, \quad \gamma_{\mathrm{E}, \min s_{\mathrm{E}}} \leq P_{\mathrm{E}}^{c} \leq \gamma_{\mathrm{E}, \max } s_{\mathrm{E}}, \\
& \dot{E}_{\mathrm{B}}^{e}=-P_{\mathrm{B} 1}^{e} \text {, } \\
& E_{\mathrm{B}}^{e}(0)=E_{\mathrm{B}}^{e}\left(t_{\mathrm{end}}\right) \text {, } \\
& P_{\mathrm{E}}^{c}=\gamma_{\mathrm{E}, \min s_{\mathrm{E}}}+\left(P_{\mathrm{A}}^{m}+P_{\mathrm{AU}}^{m}\right. \\
& \left.+\left(\gamma_{\mathrm{G} 0}+P_{\mathrm{BR}}^{m}+\gamma_{\mathrm{W} 0}+\gamma_{\mathrm{W} 1} s_{\mathrm{E}}+\gamma_{\mathrm{W} 2} s_{\mathrm{B}}\right) \gamma_{\mathrm{ML}}\right) \gamma_{\mathrm{E} 1} \text {, } \\
& P_{\mathrm{C}}^{m}=\max \left(\gamma_{\mathrm{C} 2} \frac{P_{\mathrm{E}}^{c 2}}{s_{\mathrm{E}}}+c_{\mathrm{C} 1} P_{\mathrm{E}}^{c}, 0\right) \text {, } \\
& P_{\mathrm{B} 1}^{e}=\frac{R_{c} c_{c 1} P_{\mathrm{B} 1}^{e 2}}{2 E_{\mathrm{B}}^{e}+s_{\mathrm{B}} \bar{n}_{\mathrm{B}} c_{c 1} c_{c 0}^{2}}+\gamma_{\mathrm{A} 0}+c_{\mathrm{A} 1} P_{\mathrm{A}}^{m}+c_{\mathrm{A} 2} P_{\mathrm{A}}^{m 2} \\
& +c_{\mathrm{M} 00}+c_{\mathrm{M} 01} P_{\mathrm{E}}^{c}+c_{\mathrm{M} 02} P_{\mathrm{E}}^{c 2}+c_{\mathrm{M} 1} P_{\mathrm{C}}^{m}+c_{\mathrm{M} 2} P_{\mathrm{C}}^{m 2}+P_{\mathrm{AU}}^{e},
\end{aligned}
$$


with the constraints imposed $\forall t \in\left[0, t_{\text {end }}\right]$, where $t_{\text {end }}$ is the time when the trip ends. Note that the values of all the varying coefficients $\gamma$ can be pre-computed for the entire range of the driving cycle. This is because the variations originate from the changes in vehicle speed $v_{\mathrm{V}}$, acceleration $a_{\mathrm{V}}$ or slope $\alpha$ that are given, or from one of the rotational speeds $\omega_{\mathrm{G}}, \omega_{\mathrm{E}}$ or $\omega_{\mathrm{A}}$ which can be computed using the knowledge of $v_{\mathrm{V}}$ and of the gear ratio trajectory $\lambda_{\mathrm{G}}(t)$. The trajectory $\lambda_{\mathrm{G}}(t)$ is thus assumed fixed prior to solving the convex optimization problem.

In (58) the last two equality constraints can be relaxed with inequalities by replacing "=" with " $\geq$ " sign. The relaxation changes the original formulation by creating a convex superset of the non-convex set. However, it can be logically reasoned that the resulting two constraints hold with equality at the optimum - otherwise energy would be unnecessarily wasted. Hence, the solutions of the relaxed and the non-relaxed problem are the same. For a detailed proof see [29]. This implies that the compressor power $P_{\mathrm{C}}^{m}$ may be treated as an additional optimization variable, yielding in total six time dependent, $P_{\mathrm{E}}^{c}, P_{\mathrm{BR}}^{m}, P_{\mathrm{A}}^{m}, P_{\mathrm{C}}^{m}, P_{\mathrm{B} 1}^{e}, E_{\mathrm{B}}^{e}$, and two scalar ones, $s_{\mathrm{E}}$ and $s_{\mathrm{B}}$. Also strict inequalities describing lower bounds of sizing parameters can be relaxed by means of a small constant $\varepsilon>0$. In other words, (58) may be rewritten as

$$
\begin{aligned}
& \min J=w_{\phi} \int_{0}^{t_{\mathrm{end}}} P_{\mathrm{E}}^{c} d t+w_{\mathrm{E}} s_{\mathrm{E}}+w_{\mathrm{B}} s_{\mathrm{B}}, \\
& \text { s.t. }(55),(56) \text {, } \\
& \varepsilon \leq s_{\mathrm{B}}, \quad \varepsilon \leq s_{\mathrm{E}} \leq 1, \quad 0 \leq P_{\mathrm{BR}}^{m}, \\
& \gamma_{\mathrm{A}, \text { min }} \leq P_{\mathrm{A}}^{m} \leq c_{\mathrm{A}, \text { max }}, \quad \gamma_{\mathrm{E}, \text { min }} s_{\mathrm{E}} \leq P_{\mathrm{E}}^{c} \leq \gamma_{\mathrm{E}, \text { max }} s_{\mathrm{E}}, \\
& \dot{E}_{\mathrm{B}}^{e}=-P_{\mathrm{B} 1}^{e} \text {, } \\
& E_{\mathrm{B}}^{e}(0)=E_{\mathrm{B}}^{e}\left(t_{\mathrm{end}}\right) \text {, } \\
& P_{\mathrm{E}}^{c}=\gamma_{\mathrm{E}, m i n} s_{\mathrm{E}}+\left(P_{\mathrm{A}}^{m}+P_{\mathrm{AU}}^{m}\right. \\
& \left.+\left(\gamma_{\mathrm{G} 0}+P_{\mathrm{BR}}^{m}+\gamma_{\mathrm{W} 0}+\gamma_{\mathrm{W} 1} s_{\mathrm{E}}+\gamma_{\mathrm{W} 2} s_{\mathrm{B}}\right) \gamma_{\mathrm{ML}}\right) \gamma_{\mathrm{E} 1}, \\
& \max \left(\gamma_{\mathrm{C} 2} \frac{P_{\mathrm{E}}^{c 2}}{s_{\mathrm{E}}}+c_{\mathrm{C} 1} P_{\mathrm{E}}^{c}, 0\right) \leq P_{\mathrm{C}}^{m} \leq c_{\mathrm{C}, \max } \\
& P_{\mathrm{B} 1}^{e} \geq \frac{R_{c} c_{c 1} P_{\mathrm{B} 1}^{e 2}}{2 E_{\mathrm{B}}^{e}+s_{\mathrm{B}} \bar{n}_{\mathrm{B}} c_{c 1} c_{c 0}^{2}}+\gamma_{\mathrm{A} 0}+c_{\mathrm{A} 1} P_{\mathrm{A}}^{m}+c_{\mathrm{A} 2} P_{\mathrm{A}}^{m 2} \\
& +c_{\mathrm{M} 00}+c_{\mathrm{M} 01} P_{\mathrm{E}}^{c}+c_{\mathrm{M} 02} P_{\mathrm{E}}^{c 2}+c_{\mathrm{M} 1} P_{\mathrm{C}}^{m}+c_{\mathrm{M} 2} P_{\mathrm{C}}^{m 2}+P_{\mathrm{AU}}^{e} .
\end{aligned}
$$

All the optimization variables in (59) are further scaled with their expected maximal values, the resulting problem is discretized using a zero-order hold with a sample time $\delta_{t}$ and then casted into a standard convex second order cone program (SOCP) form. The SOCP is given by

$$
\begin{aligned}
& \min J=f^{T} x \\
& \text { s.t. }\left\|A_{i} x+e_{i}\right\|_{2} \leq c_{i}^{T} x+d_{i}, \quad i=1, \ldots, . m, \\
& \quad F x=g
\end{aligned}
$$

where $x \in R^{n}$ are optimization variables, $A_{i} \in R^{n_{i} \times n}, F \in R^{p \times n}$, and $\|\cdot\|_{2}$ is Euclidean norm. Constraints of the type $z \geq x^{2} / y$ are written as

$$
\left\|\left(\begin{array}{c}
2 x \\
y-z
\end{array}\right)\right\|_{2} \leq y+z
$$

The SOCP (60) is specified and solved using the CVX optimization modeling language [30], [31], in combination with the SDPT3 solver [32].

\section{B. Gear selection strategy}

The discrete-time gear trajectory $g\left(t_{k}\right)$, with $t_{k}=k \delta_{t}$ and $k \geq 0$, is decided prior to and outside of the convex optimization. In particular, two different gear selection strategies have been implemented. The first searches for a gear that results in the largest difference between the approximate and the maximum operating torque of a baseline NA ICE, at every time instant. This is expected to promote the ICE downsizing. The second however, at every time instant finds a gear that maximizes the estimated ICE efficiency, so that a lower vehicle fuel consumption can be achieved.

These two gear selection strategies are implemented using the functions

$$
\begin{aligned}
& g^{(1)}\left(t_{k}\right)=\arg \max _{g \in\{1, \ldots 5\}}\left(\bar{\tau}_{\mathrm{E}, \max }\left(t_{k}\right)-\hat{\bar{\tau}}_{\mathrm{E}}\left(t_{k}\right)\right), \\
& g^{(2)}\left(t_{k}\right)=\arg \max _{g \in\{1, \ldots 5\}} \hat{\eta}_{\mathrm{E}}\left(t_{k}\right),
\end{aligned}
$$

where $\hat{\bar{\tau}}_{\mathrm{E}}$ and $\hat{\eta}_{\mathrm{E}}$ denote the baseline NA ICE operating torque and efficiency estimates, computed as

$$
\begin{aligned}
\hat{\bar{\tau}}_{\mathrm{E}} & =\frac{\hat{P}_{\mathrm{E}}^{m}}{\omega_{\mathrm{E}}}, \\
\hat{\eta}_{\mathrm{E}} & =\frac{\hat{P}_{\mathrm{E}}^{m}}{\gamma_{\mathrm{E} 1} \hat{P}_{\mathrm{E}}^{m}+\gamma_{\mathrm{E}, \text { min }}} .
\end{aligned}
$$

with $\hat{P}_{\mathrm{E}}^{m}$ being the estimated baseline NA ICE mechanical power, given by

$$
\hat{P}_{\mathrm{E}}^{m}=\max \left(\hat{P}_{\mathrm{A}}^{m}+P_{\mathrm{AU}}^{m}+\gamma_{\mathrm{G} 0}+\gamma_{\mathrm{W} 0}+\gamma_{\mathrm{W} 1}+\gamma_{\mathrm{W} 2}, 0\right)
$$

and $\hat{P}_{\mathrm{A}}^{m}$ the estimated alternator mechanical power, i.e.,

$$
\hat{P}_{\mathrm{A}}^{m}=\operatorname{Re}\left(\frac{-c_{\mathrm{A} 1}-\sqrt{c_{\mathrm{A} 1}^{2}-4\left(\gamma_{\mathrm{A} 0}+P_{\mathrm{AU}}^{e}\right) c_{\mathrm{A} 2}}}{2 c_{\mathrm{A} 2}}\right) .
$$

The use of torque $\hat{\bar{\tau}}_{\mathrm{E}}$, efficiency $\hat{\eta}_{\mathrm{E}}$, power $\hat{P}_{\mathrm{E}}^{m}$ and $\hat{P}_{\mathrm{A}}^{m}$ estimates, instead of their optimal values, is required since the computation of gear selection strategy precedes the convex optimization - which renders the optimal values unavailable. However, an alternative, more sophisticated gear selection strategies, employing iterative solutions of a convex problem (59), could be applied here as well. For details, see [33][35].

\section{CAse STUdy}

This section provides the case study results related to the sizing of electrically supercharged ICE powertrain. The purpose of the study is mainly to demonstrate the proposed modeling and optimization methodology. For this reason, the standard WLTP3 driving cycle has been used. Note that cycles, such as the WLTP3, are more often employed for evaluating the vehicle fuel consumption than for component sizing. Thus, for purposes a specific, real-world powertrain sizing application, one should consider replacing the WLTP3 with a different (more demanding) cycle, which would better 
suit the intended vehicle driving scenario. The values of the relevant model parameters, used in this particular study, are listed in Table II.

The duration of the chosen driving cycle, sampled at $\delta_{t}=1 \mathrm{~s}$, was $t_{\mathrm{end}}=30 \mathrm{~min}$. Thus, to find the solution of (58) it was necessary to determine the values of 1800 unknowns per each of the 6 time-dependent optimization variables, plus the two unknown scaling coefficients. For this purpose, the Microsoft Windows 7 Enterprise computer was employed, equipped with the Intel(R) Core(TM) i7-2670QM $2.20 \mathrm{GHz}$ CPU. Specifically, due to the optimization problem's convex formulation and despite its considerable size, it took less than 20 s to find its unique global optimum, along with the values of the related optimization variables. The optimization results are presented in the following.

\section{A. Optimal component sizes}

Table III summarizes the results of 6 different optimization runs. They correspond to 3 distinct engine scenarios: baseline NA ICE, downsized NA ICE and downsized SC ICE, each for 2 defined gear selection strategies: $g^{(1)}$ and $g^{(2)}$. From the presented data it is apparent that the electric supercharging has led to a substantial decrease in both the engine size $\left(1-s_{\mathrm{E}}\right)$ and the dominant fuel cost $\left(J_{\phi}\right)$. As expected, the engine size reduction is more prominent in the case of $g^{(1)}$ strategy, where gears are chosen such that they maximize the distance between the engine operating torque and its maximum torque line. In this case, the use of the MCU has resulted in $41.57 \%$ of engine volume decrease, when the downsized SC ICE is compared to the baseline NA ICE. On the other hand, more fuel is saved with $g^{(2)}$ strategy, which is reflected in the downsized SC ICE fuel cost of $6.53 \propto / \mathrm{km}$ vs. the baseline NA ICE fuel cost of $7.22 \phi / \mathrm{km}$. This is expected since $g^{(2)}$ strategy maximizes the ICE efficiency, instead of the torque difference, thereby also promoting a lower ICE fuel consumption.

Note that using (13), for a particular gear selection strategy, engine and buffer size, the demanded engine mechanical power $P_{\mathrm{E}}^{m}$ directly follows from the provided WLTP3 driving cycle data. Specifically, for all 3 considered engine scenarios and $g^{(1)}$ gear selection strategy, this yields a peak in the mechanical power demand of $P_{\mathrm{E}}^{m} \approx 38 \mathrm{~kW}$, after $t=26 \mathrm{~min}$ and $7 \mathrm{~s}$ from the beginning of the cycle. By comparing the peak power demand with the maximum baseline ICE mechanical power $\bar{P}_{\mathrm{E}, \max }^{m}$ presented in Table III, scaled by the appropriate downsizing factor $s_{\mathrm{E}}$, it can be concluded that in the first scenario the engine was clearly oversized $(45.44 \mathrm{~kW}$ vs. $38 \mathrm{~kW})$, in the second tightly sized $(38.54 \mathrm{~kW}$ vs. $38 \mathrm{~kW})$, and in the third clearly undersized $(26.55 \mathrm{~kW}$ vs. $38 \mathrm{~kW})$, w.r.t. the WLTP3 cycle requirements. This implies that in the last case the power gap was filled by the operation of the MCU via its temporary enhancement of the power production capability of the downsized ICE.

\section{B. Optimal state and control trajectories}

Apart from the optimal component sizes, the solution of the problem (59) provides also the optimal control and state trajectories for the studied driving cycle. These are shown in Fig. 7 for the case of the downsized SC ICE employing the first gear selection strategy. Indeed, it can be observed that the
TABLE II

MODEL AND DESIGN PARAMETER VALUES

\begin{tabular}{|c|c|c|}
\hline Type & Parameter & Value \\
\hline \multirow{5}{*}{ Drive cycle } & $\delta_{t}$ & $1 \mathrm{~s}$ \\
\hline & $t_{\mathrm{end}}$ & $30 \mathrm{~min}$ \\
\hline & $t_{\text {year }}$ & 1 year \\
\hline & $t_{\text {life }}$ & 15 year \\
\hline & $d_{\text {year }}$ & $12000 \mathrm{~km}$ \\
\hline \multirow{7}{*}{ Ambient } & $\rho_{\mathrm{AM}}$ & $1.184 \mathrm{~kg} / \mathrm{m}^{3}$ \\
\hline & $p_{\text {AM }}$ & $98 \mathrm{kPa}$ \\
\hline & $T_{\mathrm{AM}}$ & $298 \mathrm{~K}$ \\
\hline & $a_{g}$ & $9.81 \mathrm{~m} / \mathrm{s}^{2}$ \\
\hline & $\lambda_{\kappa}$ & 1.4 \\
\hline & $c_{p}$ & $1005 \mathrm{~J} / \mathrm{kg} / \mathrm{K}$ \\
\hline & $c_{R}$ & $287 \mathrm{~J} / \mathrm{kg} / \mathrm{K}$ \\
\hline \multirow{6}{*}{ Vehicle } & $\bar{m}_{\mathrm{V}}$ & $970 \mathrm{~kg}$ \\
\hline & $\lambda_{\mathrm{V}}$ & 1.3 \\
\hline & $r_{\mathrm{W}}$ & $29.57 \mathrm{~cm}$ \\
\hline & $c_{d}$ & 0.32 \\
\hline & $c_{r}$ & 0.01 \\
\hline & $A_{f}$ & $2.07 \mathrm{~m}^{2}$ \\
\hline Gearbox & $\begin{array}{l}{\left[c_{\mathrm{G} 0}, c_{\mathrm{G} 1}, c_{\mathrm{G} 2}\right]} \\
\lambda_{\mathrm{G}}\end{array}$ & $\begin{array}{l}{[700,3,0]} \\
{[15.2,8.2,5.3,4.0,3.3]}\end{array}$ \\
\hline \multirow{2}{*}{ Mec. power link } & $\lambda_{\mathrm{A}}$ & 1.5 \\
\hline & $P_{\mathrm{AU}}^{m}$ & $500 \mathrm{~W}$ \\
\hline \multirow{12}{*}{ ICE } & $\bar{m}_{\mathrm{E}}$ & $62.67 \mathrm{~kg}$ \\
\hline & $\bar{V}_{\mathrm{E}}$ & $1000 \mathrm{~cm}^{3}$ \\
\hline & {$\left[c_{\mathrm{vol} 0}, c_{\mathrm{vol} 1}, c_{\mathrm{vol} 2}\right]$} & {$\left[0.36,3 \cdot 10^{-3},-3.3 \cdot 10^{-6}\right]$} \\
\hline & {$\left[c_{\bar{\eta} 0}, c_{\bar{\eta} 1}, c_{\bar{\eta} 2}\right]$} & {$\left[0.4,1.1 \cdot 10^{-4},-1.7 \cdot 10^{-7}\right]$} \\
\hline & {$\left[c_{f 0}, c_{f 2}\right]$} & {$\left[3.1 \cdot 10^{4}, 0.6\right]$} \\
\hline & {$\left[c_{g 0}, c_{g 1}\right]$} & {$\left[9 \cdot 10^{4},-7.6 \cdot 10^{4}\right]$} \\
\hline & $\lambda_{e c}$ & 10 \\
\hline & $p_{\mathrm{EM}}$ & $108 \mathrm{kPa}$ \\
\hline & $\omega_{\mathrm{E}, \min }$ & $60 \mathrm{rad} / \mathrm{s}$ \\
\hline & $\omega_{\mathrm{E}, \max }$ & $680 \mathrm{rad} / \mathrm{s}$ \\
\hline & $\varepsilon_{\mathrm{E}, \text { year }}$ & $5 \%$ \\
\hline & $\mu_{\mathrm{E}}$ & $0.67 € / \mathrm{kW}$ \\
\hline \multirow{4}{*}{ Air-fuel control } & $H_{l}$ & $42.7 \mathrm{MJ} / \mathrm{kg}$ \\
\hline & $\rho_{\phi}$ & $758.8 \mathrm{~kg} / \mathrm{m}^{3}$ \\
\hline & $\lambda_{\alpha \phi}$ & 14.7 \\
\hline & $\mu_{\phi}$ & $1.216 € / 1$ \\
\hline \multirow{5}{*}{ Air system } & $\eta_{\mathrm{C}}$ & $60 \%$ \\
\hline & $\lambda_{\Pi, \max }$ & 1.58 \\
\hline & {$\left[c_{T 0}, c_{\mathrm{T} 1}\right]$} & {$[0.59,0.41]$} \\
\hline & {$\left[c_{\dot{m} 0}, c_{\dot{m} 1}\right]$} & {$[0.43,0.56]$} \\
\hline & {$\left[c_{\text {surge } 0}, c_{\text {surge } 1}\right]$} & {$\left[1.55 \cdot 10^{5}, 3.72 \cdot 10^{3}\right]$} \\
\hline \multirow{3}{*}{$\mathrm{MCU}$} & {$\left[c_{\mathrm{M} 00}, c_{\mathrm{M} 01}, c_{\mathrm{M} 02}\right]$} & {$\left[33.2,1.4 \cdot 10^{-3}, 4.8 \cdot 10^{-7}\right]$} \\
\hline & {$\left[c_{\mathrm{M} 1}, c_{\mathrm{M} 2}\right]$} & {$\left[1.09,5.01 \cdot 10^{-6}\right]$} \\
\hline & $c_{\mathrm{C}, \max }$ & $2.6 \mathrm{~kW}$ \\
\hline \multirow{3}{*}{ Alternator } & {$\left[c_{\mathrm{A} 00}, c_{\mathrm{A} 01}, c_{\mathrm{A} 02}\right]$} & {$\left[70.8,-0.2,5.5 \cdot 10^{-4}\right]$} \\
\hline & {$\left[c_{\mathrm{A} 1}, c_{\mathrm{A} 2}\right]$} & {$\left[-0.8,6.8 \cdot 10^{-5}\right]$} \\
\hline & $c_{\mathrm{A}, \max }$ & $2.4 \mathrm{~kW}$ \\
\hline El. power link & $P_{\mathrm{AU}}^{e}$ & $300 \mathrm{~W}$ \\
\hline \multirow{10}{*}{ Battery } & $\bar{n}_{\mathrm{B}}$ & 4 \\
\hline & $\bar{m}_{c}$ & $80 \mathrm{~g}$ \\
\hline & $Q_{c}$ & $2.3 \mathrm{Ah}$ \\
\hline & $c_{c 0}$ & $3.27 \mathrm{~V}$ \\
\hline & $c_{c 1}$ & $58 \mathrm{kF}$ \\
\hline & $R_{C}$ & $11.5 \mathrm{~m} \Omega$ \\
\hline & $i_{c, \min / \max }$ & $\mp 35 \mathrm{~A}$ \\
\hline & $S O c_{\min / \max }$ & $\{20,80\} \%$ \\
\hline & $\varepsilon_{\mathrm{B}, \text { year }}$ & $5 \%$ \\
\hline & $\mu_{\mathrm{B}}$ & $500 € / \mathrm{kWh}$ \\
\hline
\end{tabular}

MCU is mostly activated during high power demands that are mostly presented near the end of the cycle. As a consequence, this reduces the load on the ICE and allows it to be downsized. Furthermore, it can be seen that the energy stored in the buffer at the end of the cycle is the same as the one stored in the beginning. This implies that all the energy consumed by the MCU is ultimately compensated by the work of the alternator. 
TABLE III

OPTIMIZATION RESULTS

\begin{tabular}{|c|c|c|c|}
\hline Case & Parameter & $g^{(1)}$ & $g^{(2)}$ \\
\hline \multirow{5}{*}{$\begin{array}{l}\text { Baseline \& } \\
\text { naturally-aspirated }\end{array}$} & $J$ & $8.98 \notin / \mathrm{km}$ & $7.25 \phi / \mathrm{km}$ \\
\hline & $J_{\phi}$ & $8.95 \notin / \mathrm{km}$ & $7.22 \phi / \mathrm{km}$ \\
\hline & $\bar{P}_{\mathrm{E}, \max }^{m}$ & $45.44 \mathrm{~kW}$ & $45.44 \mathrm{~kW}$ \\
\hline & $\bar{E}_{\mathrm{B}, \max }^{e}$ & $0.03 \mathrm{kWh}$ & $0.03 \mathrm{kWh}$ \\
\hline & $1-s_{\mathrm{E}}$ & $0 \%$ & $0 \%$ \\
\hline \multirow{5}{*}{$\begin{array}{l}\text { Downsized \& } \\
\text { naturally-aspirated }\end{array}$} & $J$ & $8.29 \notin / \mathrm{km}$ & $7.19 \phi / \mathrm{km}$ \\
\hline & $J_{\phi}$ & $8.25 \phi / \mathrm{km}$ & $7.14 \phi / \mathrm{km}$ \\
\hline & $\bar{P}_{\mathrm{E}, m a x}^{m} s_{\mathrm{E}}$ & $38.54 \mathrm{~kW}$ & $44.89 \mathrm{~kW}$ \\
\hline & $\bar{E}_{\mathrm{B}, \max }^{e} s_{\mathrm{B}}$ & $0.07 \mathrm{kWh}$ & $0.06 \mathrm{kWh}$ \\
\hline & $1-s_{\mathrm{E}}$ & $15.18 \%$ & $1.21 \%$ \\
\hline \multirow{5}{*}{$\begin{array}{l}\text { Downsized \& } \\
\text { supercharged }\end{array}$} & $J$ & $7.36 \notin / \mathrm{km}$ & $6.63 \phi / \mathrm{km}$ \\
\hline & $J_{\phi}$ & $7.26 \notin / \mathrm{km}$ & $6.53 \phi / \mathrm{km}$ \\
\hline & $\bar{P}_{\mathrm{E}, \max }^{m} s_{\mathrm{E}}$ & $26.55 \mathrm{~kW}$ & $31.87 \mathrm{~kW}$ \\
\hline & $\bar{E}_{\mathrm{B}, \max }^{e} s_{\mathrm{B}}$ & $0.23 \mathrm{kWh}$ & $0.21 \mathrm{kWh}$ \\
\hline & $1-s_{\mathrm{E}}$ & $41.57 \%$ & $29.85 \%$ \\
\hline
\end{tabular}

\section{DisCUSSION AND CONCLUSIONS}

This paper presented convex modeling steps for the problem of optimal ICE and electric energy storage buffer sizing, in the case of the electrically supercharged ICE powertrain concept. In this context, the electric supercharging was used to help the engine during short-duration, high-power demands. The underlying optimization problem was formulated as the minimization of the vehicle operational (fuel) and component (the ICE and electric buffer) costs on a given driving cycle. The optimization problem was solved for the WLTP3 cycle which delivered not only the optimal component sizes but also the optimal control (e.g., engine fuel power) and state (e.g., buffer energy) trajectories. In the analyzed scenario, the fuel cost savings of up to $10 \%$ were obtained, showing that the engine downsizing via electric supercharging could constitute a promising fuel-saving mechanism.

This research could be extended in at least two different directions. The first would be to consider also the sizing of the vehicle alternator, compressor and gearbox, so that they match the electrically supercharged downsized engine more precisely. The second would be to evaluate the investigated powertrain concept on a more-demanding driving cycle, or a few of them, consisting of prolonged high-load intervals. To this end, it could also be beneficial to adapt the developed convex modeling and optimization method towards a powertrain topology utilizing an electrified turbocharger. In this case, the inclusion of the electric motor could help improve the compromised torque capability of downsized, turbocharged ICEs, at low engine speeds - whereas long-duration, highpower demands could be handled solely by the conventional turbocharging.

\section{ACKNOWLEDGMENT}

The authors gratefully acknowledge the financial support from the EU Eureka Program (Project \# 5765 - WETREN).

\section{REFERENCES}

[1] S. M. Shahed and K.-H. Bauer, "Parametric Studies of the Impact of Turbocharging on Gasoline Engine Downsizing," SAE International Journal of Engines, vol. 2, no. 1, pp. 2009-01-1472, apr 2009.

[2] P. Leduc, B. Dubar, A. Ranini, and G. Monnier, "Downsizing of Gasoline Engine: an Efficient Way to Reduce $\mathrm{CO}_{2}$ Emissions," Oil \& Gas Science and Technology, vol. 58, no. 1, pp. 115-127, jan 2003.
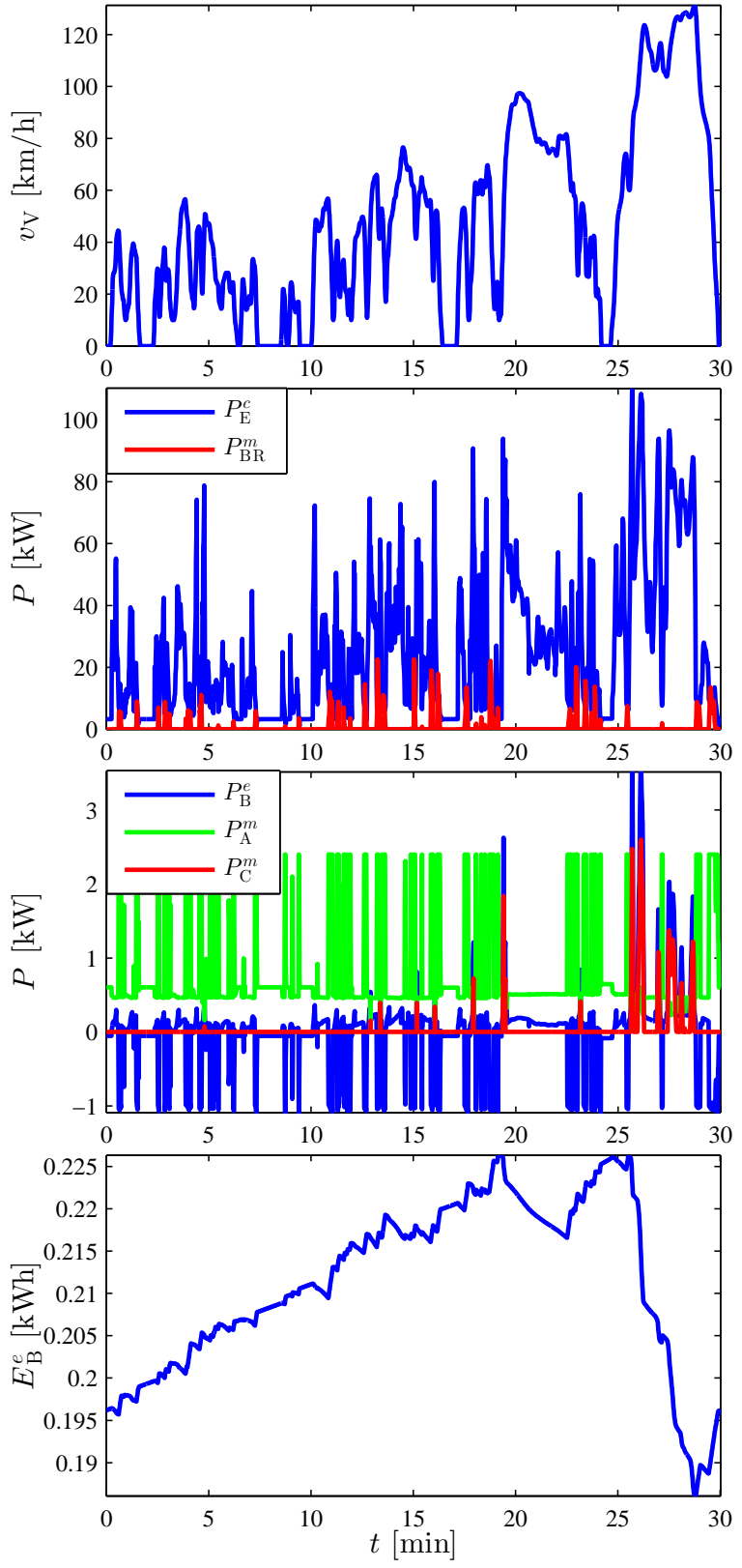

Fig. 7. Optimal control and state trajectories for a vehicle with the downsized SC ICE employing the gear selection strategy that maximizes the difference between the approximate and the maximum operating torque of a baseline NA ICE.

[3] J. Wang, Z. Xia, and D. Howe, "Three-Phase Modular Permanent Magnet Brushless Machine for Torque Boosting on a Downsized ICE Vehicle," IEEE Transactions on Vehicular Technology, vol. 54, no. 3, pp. 809-816, may 2005.

[4] Jiabin Wang, B. Taylor, Zhigang Sun, and D. Howe, "Experimental characterization of a supercapacitor-based electrical torque-boost system for downsized ICE vehicles," IEEE Transactions on Vehicular Technology, vol. 56, no. 6, pp. 3674-3681, nov 2007.

[5] N. Fraser, H. Blaxill, G. Lumsden, and M. Bassett, "Challenges for Increased Efficiency through Gasoline Engine Downsizing," SAE International Journal of Engines, vol. 2, no. 1, pp. 2009-01-1053, apr 2009.

[6] A. Lefebvre and S. Guilain, "Modelling and Measurement of the Transient Response of a Turbocharged SI Engine," SAE Technical Paper 2005-01-0691, 2005.

[7] J. Villegas, B. Gao, K. Svancara, W. Thornton, and J. Parra, "Realtime simulation and control of an electric supercharger for engine 
downsizing," in IEEE Vehicle Power and Propulsion Conference, 2011, pp. 1-6.

[8] N. Chayopitak, R. Pupadubsin, S. Karukanan, and P. Champa, "Design of a $1.5 \mathrm{~kW}$ high speed switched reluctance motor for electric supercharger with optimal performance assessment," in 15th International Conference on Electrical Machines and Systems, Sapporo, 2012, pp. $1-5$.

[9] S. Kachapornkul, P. Somsiri, R. Pupadubsin, and N. Nulek, "Low cost high speed switched reluctance motor drive for supercharger applications," in 15th International Conference on Electrical Machines and Systems, Sapporo, 2012, pp. 1-6.

[10] B. Lequesne, "Automotive Electrification: The Nonhybrid Story," IEEE Transactions on Transportation Electrification, vol. 1, no. 1, pp. 40-53, jun 2015.

[11] D. Assanis, G. Delagrammatikas, R. Fellini, Z. Filipi, J. Liedtke, N. Michelena, P. Papalambros, D. Reyes, D. Rosenbaum, A. Sales, and M. Sasena, "An optimization approach to hybrid electric propulsion system design," Journal of Mechanics of Structures and Machines, Automotive Research Center Special Edition, vol. 27, no. 4, pp. 393 421,1999

[12] V. Galdi, L. Ippolito, A. Piccolo, and A. Vaccaro, "A genetic-based methodology for hybrid electric vehicles sizing," Soft Computing - A Fusion of Foundations, Methodologies and Applications, vol. 5, no. 6, pp. 451-457, 2001.

[13] L. Wu, Y. Wang, X. Yuan, and Z. Chen, "Multiobjective optimization of HEV fuel economy and emissions using the self-adaptive differential evolution algorithm," IEEE Transactions on Vehicular Technology, vol. 60, no. 6, pp. 2458-2470, 2011.

[14] H. Fathy, P. Papalambros, and A. Ulsoy, "On combined plant and control optimization," in 8th Cairo University International Conference on Mechanical Design and Production, Cairo University, 2004.

[15] D. L. Peters, P. Y. Papalambros, and A. G. Ulsoy, "Sequential codesign of an artifact and its controller via control proxy functions," Mechatronics, vol. 23, no. 4, pp. 409-418, 2013.

[16] T. Nüesch, P. Elbert, M. Flankl, C. Onder, and L. Guzzella, "Convex Optimization for the Energy Management of Hybrid Electric Vehicles Considering Engine Start and Gearshift Costs," Energies, vol. 7, no. 2, pp. 834-856, feb 2014.

[17] J. A. Reyer and P. Y. Papalambros, "Combined optimal design and control with application to an electric dc motor," Journal of Mechanical Design, vol. 142, no. 2, pp. 183-191, 2002.

[18] E. Tara, S. Shahidinejad, S. Filizadeh, and E. Bibeau, "Battery storage sizing in a retrofitted plug-in hybrid electric vehicle," IEEE Transactions on Vehicular Technology, vol. 59, no. 6, pp. 2786-2794, 2010.

[19] Z. Filipi, L. Louca, B. Daran, C.-C. Lin, U. Yildir, B. Wu, M. Kokkolaras, D. Assanis, H. Peng, P. Papalambros, J. Stein, D. Szkubiel, and $\mathrm{R}$. Chapp, "Combined optimisation of design and power management of the hydraulic hybrid propulsion systems for the 6 x 6 medium truck," International Journal of Heavy Vehicle Systems, vol. 11, no. 3, pp. 372402, 2004.

[20] M. Kim and H. Peng, "Power management and design optimization of fuel cell/battery hybrid vehicles," Journal of Power Sources, vol. 165, no. 2, pp. 819-832, 2007.

[21] O. Sundström, L. Guzzella, and P. Soltic, "Torque-assist hybrid electric powertrain sizing: From optimal control towards a sizing law," IEEE Transactions on Control Systems Technology, vol. 18, no. 4, pp. 837849,2010

[22] S. Boyd and L. Vandenberghe, Convex Optimization. Cambridge University Press, 2004.

[23] B. de Jager, "Predictive storage control for a class of power conversion systems," in Proceedings of European Control Conference, Cambridge, UK, sep 2003.

[24] L. Guzzella and C. H. Onder, Introduction to Modeling and Control of Internal Combustion Engine Systems. Springer-Verlag, 2010.

[25] B. de Jager, T. van Keulen, and J. Kessels, Optimal Control of Hybrid Vehicles. Springer London, 2013.

[26] L. Guzzella and A. Sciarretta, Vehicle Propulsion Systems, 3rd ed. Berlin, Heidelberg: Springer, Verlag, 2013.

[27] B. Egardt, N. Murgovski, M. Pourabdollah, and L. Johannesson, "Electromobility studies based on convex optimization: Design and control issues regarding vehicle electrification," IEEE Control Systems Magazine, vol. 34, no. 2, pp. 32-49, 2014.

[28] M. Pourabdollah, N. Murgovski, A. Grauers, and B. Egardt, "Optimal sizing of a parallel PHEV powertrain," IEEE Transactions on Vehicular Technology, vol. 62, no. 6, pp. 2469-2480, 2013.

[29] N. Murgovski, L. Johannesson, X. Hu, B. Egardt, and J. Sjöberg, "Convex relaxations in the optimal control of electrified vehicles," in American Control Conference, Chicago, USA, 2015.

[30] M. Grant and S. Boyd, "CVX: Matlab Software for Disciplined Convex Programming, version 2.1," mar 2014.
[31] — " "Graph Implementations for Nonsmooth Convex Programs," in Recent Advances in Learning and Control. London: Springer London, 2008, pp. 95-110.

[32] K. C. Toh, M. J. Todd, and R. H. Tutuncu, "SDPT3 - a Matlab software package for semidefinite programming," Optimization Methods and Software, vol. 11, pp. 545-581, 1999.

[33] M. Pourabdollah, N. Murgovski, A. Grauers, and B. Egardt, "An iterative dynamic programming/convex optimization procedure for optimal sizing and energy management of PHEVs," in IFAC World Congress, Cape Town, South Africa, 2014, pp. 6606-6611.

[34] T. Nüesch, P. Elbert, M. Flankl, C. Onder, and L. Guzzella, "Convex optimization for the energy management of hybrid electric vehicles considering engine start and gearshift costs," Energies, vol. 7, no. 2, pp. 834-856, 2014.

[35] V. Ngo, T. Hofman, M. Steinbuch, and A. Serrarens, "Optimal Control of the gearshift command for hybrid electric vehicles," IEEE Transactions on Vehicular Technology, vol. 61, no. 8, pp. 3531-3543, 2012.

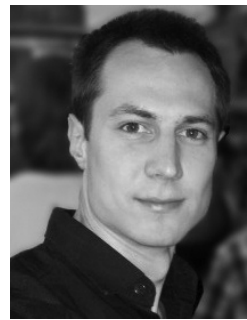

Sava Marinkov was born in Novi Sad, Republic of Serbia, in 1986. He received the M.Sc. degree (cum laude) in Mechanical Engineering in 2011 from the Eindhoven University of Technology (TU/e), Eindhoven, The Netherlands. Currently, he is a $\mathrm{Ph} . \mathrm{D}$. candidate with the Control Systems Technology group, Department of Mechanical Engineering, TU/e. His research interests include modeling, optimization and control of automotive and high-tech mechatronics systems.

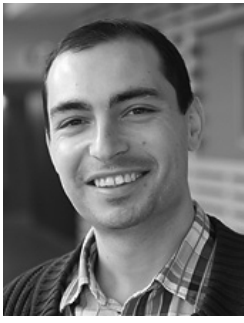

Nikolce Murgovski received the M.Sc. degree in software engineering from University West, Trollhättan, Sweden, in 2007, and the M.Sc. degree in applied physics and the Ph.D. degree in signals and systems from Chalmers University of Technology, Gothenburg, Sweden, in 2007 and 2012, respectively. $\mathrm{He}$ is currently an Assistant Professor with the Department of Signals and Systems, Chalmers University of Technology. His research interests include optimal control and dimensioning of automotive powertrains.

Bram de Jager received the M.Sc. degree in mechanical engineering from Delft University of Technology, Delft, The Netherlands, and the Ph.D. degree from the Eindhoven University of Technology, Eindhoven, The Netherlands. Currently, he is with the TU/e. He was with the Delft University of Technology and with Stork Boilers BV, Hengelo, The Netherlands. His research interests include robust control of (nonlinear) mechanical systems, integrated control and structural design, control of fluidic systems, control structure design, and applications of (nonlinear) optimal control. 